\title{
LEONOR DE SICILIA Y SANTA CLARA DE TERUEL: LA FUNDACIÓN REGINAL DE UN CONVENTO DE CLARISAS Y SU PRIMER DESARROLLO ${ }^{1}$
}

\author{
LEONOR OF SICILY AND SANTA CLARA DE TERUEL: \\ THE QUEENLY FOUNDATION OF A CONVENT \\ OF POOR CLARES AND ITS INITIAL DEVELOPMENT
}

\author{
SEBASTIAN ROEBERT \\ Universität Leipzig / Universitat de Barcelona
}

Resumen: La historia del monasterio de las clarisas de Teruel, conocido tanto por el nombre de Santa Catalina como por el de Santa Clara de Teruel, nos resulta hasta el día de hoy prácticamente desconocida. Seguramente, este hecho se debe en buena medida a la destrucción completa del archivo conventual durante la Guerra Civil. El presente estudio pretende reconstruir el proceso fundacional y analizar el primer desarrollo del monasterio, desde su creación en el año 1367 hasta el primer cuarto del siglo XV, a través de la documentación que se conserva en otros archivos y que permanece, en su mayor parte, inédita y sin estudiar. Además, se investigará el papel preponderante que desempeñó la fundadora y principal promotora del convento, Leonor de Sicilia (1349-1375), reina de la Corona de Aragón.

Palabras claves: monasterio de Santa Clara de Teruel; Leonor de Sicilia; reginalidad; monacato femenino.

\begin{abstract}
Summary: The history of the monastery of the Poor Clares of Teruel, also known as Santa Catalina or Santa Clara de Teruel, is virtually unknown. One reason for the lack of studies dedicated to this convent is the complete loss of its archive during the Spanish Civil War. The present study intends to reconstruct the foundation and initial development of Santa Clara de Teruel from its beginning in 1367 until the first quarter of the 15th century, using mostly hitherto unknown sources from other archives. Special attention will be paid to the founder of the monastery, Leonor of Sicily (1349-1375), queen of the Crown of Aragon.
\end{abstract}

Keywords: monastery of Santa Clara de Teruel; Leonor of Sicily; queenship; female monasticism.

1 Abreviaturas utilizadas: ACA = Archivo de la Corona de Aragón; ADZ = Archivo diocesano de Zaragoza; AHPT = Archivo histórico provincial de Teruel; ARP = Arxiu del Reial Patrimoni; ASV = Archivio Segreto Vaticano; BF = K. Eubel, Bullarium Franciscanum; Canc. = Cancelleria; MR = Maestre Racional; RACO = Registro de Actos Comunes. Agradezco a la Dra. Elia Hernández Socas la revisión lingüística del texto. 


\section{SUMARIO}

1. Introducción: reginalidad y promoción espiritual.- 2. Santa Clara de Teruel como ejemplo de la promoción espiritual: planificación, realización, solidificación.- 3. Conclusiones: Leonor de Sicilia y el potencial de su promoción espiritual.- 4. Bibliografía citada.- 6. Anexos: Tabla e imágenes.

\section{INTRODUCCIÓN: REGINALIDAD Y PROMOCIÓN ESPIRITUAL}

Las fundaciones de monasterios figuran normalmente entre las actividades que se atribuyen a las reinas medievales, tanto por parte de la historiografía moderna como por parte de sus propios contemporáneos. No obstante, su realización presuponía un amplio cúmulo de requisitos: la voluntad de realizar la fundación, los recursos necesarios para ello y, además, un alto grado de influencia ${ }^{2}$. En la segunda mitad del siglo XIV, la actividad de las soberanas en la Península Ibérica como fundadoras de monasterios fue en cierto modo poco significativa, probablemente debido a la carencia de alguno de estos requisitos pero, sobre todo, a las difíciles condiciones de la época ${ }^{3}$. Este hecho contrastaría con la situación específica de las reinas en la Península Ibérica, las cuales estaban capacitadas para ejercer una política y un patronazgo religioso activos gracias a los bienes propios de que disponían ${ }^{4}$. Sin embargo, se encuentran ejemplos que demuestran que la voluntad de ejercer una influencia precisamente a través de un patronazgo activo siguió vigente. Entre ellos se encuentra el del monasterio de clarisas de Santa Catalina o Santa Clara de Teruel que fue fundado en el Aragón meridional por la reina Leonor de Sicilia (1349-1375)5, esposa de Pedro IV el Ceremonioso (13361387). Este convento, junto con el de Santa Clara de Calatayud y el de Santa María de Sigena, fue objeto de la más importante actividad de patronazgo por parte de Leonor de Sicilia ${ }^{6}$.

En general, los monasterios de Aragón y, entre ellos especialmente los femeninos, siguen careciendo de estudios exhaustivos y profundos, al

\footnotetext{
${ }^{2}$ M. García, El entorno femenino, pp. 341-350.

${ }^{3}$ Para la situación en Castilla véase $\mathrm{M}^{\mathrm{a}}$ del M. Graña, Reinas y en Portugal véase A. Rodrigues, Espiritualidade, sobre todo p. 205-206.

4 J. Bianchini, The Queen's Hand, p. 6 enfatiza este aspecto como crucial para el ejercicio del poder por parte de Berenguela de Castilla.

${ }^{5}$ El estudio más exhaustivo se publicó en los años veinte del siglo XX: U. Deibel, La reyna Elionor. La promoción religiosa en general y las relaciones entre la reina y S. Clara de Teruel solo se esbozan y no se estudian en detalle.

${ }^{6}$ Ibidem, pp. 385, 391, 424
} 
contrario de lo que ocurre con los de otras regiones de la Península Ibérica ${ }^{7}$. Además, muchas de las obras recientes son incompletas y se limitan a trazar un breve esbozo de la institución a la que se refieren ${ }^{8}$; así sucede por ejemplo en el caso de Santa Clara de Teruel. La historiografía local o regional solo ofrece información de carácter general sobre su fundación que, además, no siempre está atestiguada por la documentación conservada. Por consiguiente, el presente estudio no puede recurrir a estudios comparativos en el marco de la historiografía local o regional dedicada a los monasterios en el reino de Aragón. Santa Clara de Teruel representa una fundación real muy importante en la Corona de Aragón en la segunda mitad del siglo XIV, que se emprendió después de sosegarse las acciones bélicas más duras de la llamada Guerra de los dos Pedros. Se trata además de uno de los solo cinco conventos de clarisas fundados por iniciativa real en el ámbito de la Corona de Aragón ${ }^{9}$, y el primer monasterio femenino fundado en Teruel. Hasta la primera mitad del siglo XVII debió haber mantenido este estatus ${ }^{10}$. Tanto sus orígenes como su historia en general siguen entre brumas, pues especialmente Santa Clara carece hasta hoy prácticamente de estudios. Tan sólo se han publicado unas pocas fuentes que comprenden exclusivamente documentos relacionados con la fundación del monasterio ${ }^{11}$. La historiografía franciscana solo aporta datos muy generales en cuanto a la fundación y la concesión de privilegios por parte de la Curia Romana poco tiempo después ${ }^{12}$. En cambio, la historiografía local da información un poco más detallada referida, sobre todo, a épocas posteriore $^{13}$. pero ésta requiere, sin embargo, una mirada y valoración críticas. Un problema muy grave para el estudio de Santa Clara de Teruel es la escasez de

7 Véase la colección más reciente sobre monasterios femeninos y promoción religiosa de B. Garí, Redes femeninas. Dos estudios recientes sobre las Clarisas de S. Antoni de Barcelona y S. Maria de Pedralbes: N. Jornet, El monestir de Sant Antoni; A. Castellano, Pedralbes.

8 Véase la obra de difusión sobre los monasterios aragoneses A. Ubieto, Los monasterios. Santa Clara de Teruel no se incluyó en este panorama general.

${ }^{9}$ Cuadro de conjunto en M.C. Roussey, M.P. Gounon, Nella tua tenda, p. 234.

10 J.J. Polo, Eclesiásticos, p. 700.

11 A. López, Documentos; idem, Convento; A. Rubió, Documents, vol. 1, $\mathrm{n}^{\circ} 218$ y vol. 2, $\mathrm{n}^{\mathrm{o}} 103,157,165$.

12 F. Gonzaga, De Origine, pp. 710-711; L. Wadding, Annales, p. 220; J.A. de Hebrera, Chronica, pp. 199-200.

13 J.G. Sánchez, Diario. La edición publicada por Gabriel Llabrés y Quintana no ofrece información crítica y tampoco ningún indicio sobre la localización del manuscrito. La tradición manuscrita se halla hoy en día en el Arxiu del Regne de Mallorca, Diversos, 37A/7 a y 37A/7 b. Se desconoce la forma cómo llegó el manuscrito a Mallorca. Cabe suponer que el mismo Gabriel Llabrés lo trajera de Teruel. Las informaciones que proporciona el Diario son, al parecer, bastante precisas, ya que Juan Gaspar Sánchez Muñoz informa de las fechas de expedición de los privilegios reales otorgados a Santa Clara de Teruel, J.G. Sánchez, Diario, p. 74; sobre Juan Gaspar Sánchez Muñoz véase G. Navarro, Muñoces, pp. 741-743. 
fuentes originales. Durante la Guerra Civil, se perdió el archivo conventual y con él una cantidad importante de documentos claves para la historia del monasterio. Cabe mencionar, a modo de ejemplo, que no se ha conservado un documento de tanta relevancia como el acta fundacional firmada entre la reina Leonor y las monjas en presencia del ministro provincial de los franciscanos, Bernardus Bruni. Este hecho se ha de deducir de su mención en los deberes oracionales del monasterio insertados en la donación de una renta por parte de la reina ${ }^{14}$. Del acta fundacional se habría podido derivar información valiosa sobre la configuración inicial del convento como, por ejemplo, la composición inicial de las monjas que lo constituyeron ${ }^{15}$. Debido a dicha pérdida, resulta difícil reconstruir la historia de Santa Clara de Teruel y hay que intentar llevarlo a cabo a través de la localización de fuentes documentales referentes al monasterio en otros archivos ${ }^{16}$.

Especialmente importantes son los fondos del Archivo de la Corona de Aragón de Barcelona ${ }^{17}$. El Archivo Histórico Provincial de Teruel proporciona, a través de los albaranes conservados, indicios de las relaciones económicas y sociales entre la ciudad y la comunidad de las aldeas de Teruel, por un lado, y el monasterio, por el otro. Algunas informaciones del período que va de finales del siglo XV hasta el XVIII, que también atañe a la relación entre el convento y la ciudad, se encuentran en el Archivo Histórico Nacional de Madrid ${ }^{18}$. Los privilegios pontificales se limitan aparentemente a aquellos que ya están publicados por Atanasio López ${ }^{19}$ y el Bullarium

14 ACA, Canc., Reg. 1577, f. 106v [1], Barcelona, 1368 diciembre 1. Se copiaron las obligaciones "ex speciali pacto inhito et firmato ac facto inter Nos et vos [dicta abbatissa et conventus], presente religioso viro fratre Bernardo Bruni, in sacra pagina professore ac generali ministro in provincia Aragonum" donde se habían fijado inicialmente.

${ }_{15} \mathrm{La}$ acta de la refundación de Leonor de Sicilia del convento de clarisas se concluyó en el coro de la iglesia del nuevo monasterio intramuros; asistieron la abadesa y todas las 21 hermanas del convento, las cuales firmaron el documento, ACA, Canc., Reg. 1574, f. 47r [1], Calatayud, 1366 mayo 18.

${ }^{16}$ El Centro de Documentación Ibercaja en la Biblioteca José Sinués de Zaragoza fue de gran ayuda en la búsqueda de la documentación archivística. Aprovecho para agradecerles a María José y Nuria la ayuda y el apoyo prestados.

${ }^{17}$ Se revisaron los registros de Leonor de Sicilia (1563-1585) y además las series Gratiarum de Juan I, Martín I y Ferrando I. Mediante los índices de Josep Llaris, que se consultaron hasta el volumen 18 (Ferrando II), fue posible ubicar otros documentos sobre Santa Clara de Teruel. Ya que los llamados índices no registran el contenido entero de los registros, podrían localizarse más documentos sobre el convento a través de una búsqueda en los mismos registros. La serie Maestre Racional fue revisada también hasta el reinado de Ferrando I a la que se suman los volúmenes de Alfonso V y María de Castilla que solo se conservan parcialmente.

18 A. Sanz, Los documentos, pp. 388-390. Para Santa Clara de Teruel se indican en total 18 documentos para el período de 1497 hasta 1760 y entre ellos cuatro documentos de esta fase hasta el año 1600.

19 A. López, Documentos, pp. 429-430. 
Franciscanum $^{20}$. Debido a la pérdida del archivo conventual, los registros del Vaticano constituyen la única tradición manuscrita sobre los privilegios procedentes de la Curia Romana. En suma, teniendo en cuenta el estado actual de la investigación, la fase mejor documentada corresponde a los primeros 40 años de la historia de Santa Clara de Teruel. A partir de aproximadamente 1410 disminuye el volumen de la documentación. Sin embargo, una búsqueda sistemática en los archivos debería desvelar otros hallazgos. Por los motivos expuestos anteriormente, tan solo se puede presentar en este estudio un estado provisional y relativamente modesto que puede servir como punto de partida para futuras investigaciones. Esta contribución se restringe, por lo tanto, a la reelaboración de la historia fundacional de Santa Clara de Teruel tomando como base la documentación que está, en su mayor parte, inédita. En este contexto se presenta, a continuación, la dotación inicial del convento que se puede reconstruir detalladamente a partir de las fuentes. Así mismo, se pueden seguir con bastante precisión las circunstancias que rodearon la fundación y el desarrollo del monasterio en las primeras décadas de su existencia. Por otro lado se indagarán los móviles que llevaron a la reina a promover la construcción del monasterio justamente en Teruel y la edificación de un monasterio de clarisas. Más allá de esto, también es posible bosquejar la composición social del convento y las personas relacionadas con él, así como la dotación con objetos de arte, relíquias y objetos litúrgicos. Toda esta información permite obtener una imagen bastante precisa de la fase inicial de la historia de Santa Clara de Teruel. Este bosquejo solamente es una aproximación previa a la historia del convento y trata de abrir un camino para enmarcar los datos acerca de esta fundación en un contexto más general del desarrollo del patronazgo reginal y también aquel de la orden de las Clarisas.

\section{SANTA ClARA DE TERUEL COMO EJEMPLO DE LA PROMOCIÓN ESPIRITUAL: PLANIFICACIÓN, REALIZACIÓN, SOLIDIFICACIÓN}

La fecha de fundación de Santa Clara de Teruel es incierta. En la bibliografía historiográfica suele hablarse de la existencia de un convento de clarisas en las afueras de Teruel, que debería haber existido antes de la fundación del monasterio dentro de la ciudad. De acuerdo con esta información, las monjas se habrían instalado en el llamado Campo de Santa Catalina en el año 1336 y se habrían trasladado a la ciudad, es decir, dentro de las murallas,

\footnotetext{
${ }^{20} \mathrm{BF}, \mathrm{n}^{\circ} 1121,1134,1155$.
} 
después de la donación del palacio, como muy tarde en el año $1369^{21}$. Esta hipótesis se funda probablemente en la narración de Francesco Gonzaga, que nos informa, de hecho, de su fundación en el año 1336, aunque no llega a ubicar el convento en un lugar concreto. Este último aspecto es especialmente importante, puesto que en esto Gonzaga difiere de las crónicas posteriores. En todo caso, este autor atribuye claramente la fundación a Leonor de Sicilia, como se deduce de la descripción de las relaciones familiares de la fundado$\mathrm{ra}^{22}$. Gonzaga debió de conocer bien el reinado de Leonor de Sicilia, con lo cual un error cronológico de magnitud de más de treina años resulta bastante improbable. La fecha de fundación aportada en su crónica (1336) se puede tal vez explicar por un error tipográfico. Lucas Wadding habla de una fundación anterior del convento en las afueras de la ciudad y de su traslado a la zona amurallada al referirse a una supuesta mención de este hecho en el acta de donación del palacio ${ }^{23}$. José Antonio de Hebrera adaptó en su historia de la provincia franciscana de Aragón al inicio del siglo XVIII esta descripción de los dos autores mencionados e incluye como Wadding la existencia previa de un asentamiento extramuros ${ }^{24}$. Por lo tanto, todas las crónicas suprarregionales son bastante unánimes a la hora de datar la fundación de Santa Clara de Teruel en torno a los años treinta del siglo XIV. En cambio, la localización del convento fuera de la ciudad se menciona por primera vez en el siglo XVII y, por lo tanto, con bastante posterioridad. El proceso de fundación y la historia temprana del convento se describen en estas crónicas en términos generales.

${ }^{21}$ C. Sánchez, Ma Fernanda, Reseña,p. 174; S. Sebastián, Á. Solaz, Teruel, p. 207; J.J. Polo, Eclesiásticos, p. 700 se refiere sin precisar la fecha a un asentamiento de las clarisas a inicios del siglo XIV.

${ }^{22}$ F. Gonzaga, De origine, p. 710: "Quanta fuerit serenissimae, pariter ac pientissimae Leonorae serenissimi Petri huius nominis quarti coniugis, ac filiae serenissimi Regis Siculorum, ad Deum pietas, quantaque ad Clarissas deuotio, hinc facile coniectare licet. Cum enim prefatis sororibus conuentum Bilbilis, anno Domini 1336. praefato serenissimo Petro Regi eius coniugi, a quo summe diligebatur, eo quod ei peperisset dilectissimum Principem Ioannem, qui postea in Regno ei successit, \& Martinum, qui Dux Montis albi effectus fuit, \& Leonoram, quae nupsit serenissimo Principi Ioanni Castellae Regis filio, precata est, ut regiam, quam Turolii erexerat, quando oppidum Turolium civitatis titulis, \& insignibus ornavit, ei concedere dignaretur, ad hoc ut ipsam in monasterii formam, sub invocatione beatae virginis \& martyris Catharinae, redigeret; cuius vocis annuente pietissimo Rege, ipso quod pie cogitaverat anno a partu Virgineo 1369. piissime opere adimplevit, \& monasterium omnibus numeris absolutum, \& amplissimis dotatum, ac cumulatum redditibus, Clarissis monialibus, quibus addictissima erat, inhabitandum tradidit".

23 L. Wadding, Annales, p. 220: “Attamen ex ipso donationis instrumento manifeste convincitur, extra urbem prius habitasse Sorores, eoque in loco putant aliqui, quo adhuc possident aliqua nemora \& pascua ad III. M. P. a civitate". Esta opinión aparece formulada de modo semejante en la primera edición (vol. 4, Lyon 1637, p. 133).

24 J.A. de Hebrera, Chronica, p. 199: "Fundòse este Convento en lo antiguo algo distante de la Ciudad, donde vivian las Religiosas con mucho exemplo y edificacion, veneradas como verdaderas Esposas de Jesu Christo". 
Las crónicas locales, por su parte, ofrecen información diferente. Así, la Crónica de los jueces de Teruel del siglo XVI no se pronuncia en cuanto a la existencia de un monasterio de clarisas antes del año 1360. Un asentamiento anterior a ellas, sea extra o intramuros, no se encuentra además registrado en ninguna fuente documental coetánea, ni siquiera en la donación del palacio por parte del rey Pedro IV mencionada por Wadding. Este silencio unánime de la documentación relacionada con Santa Clara de Teruel -que, por otra parte, en la fase inicial es bastante abundante- contrasta con la información proporcionada por las narraciones de las crónicas posteriores y las pone en tela de juicio. Aparte de la información ofrecida por Wadding, la localización del convento extramuros en fecha temprana podría remontarse a una confusión con una ermita que disponía de una iglesia dedicada a santa Catalina y que se hallaba cerca de la ciudad. Dicha ermita existió durante algún tiempo, por lo menos hasta comienzos del siglo XV, paralelamente a Santa Clara de Teruel ${ }^{25}$. Además, se atestigua la doble denominación del monasterio con la invocación de Santa Catalina y el nombre de la santa de la orden, Santa Clara, a partir de la fundación, lo cual seguramente contribuyó a esta confusión.

Poco tiempo después del inicio de su reinado, Leonor de Sicilia tenía ya la intención de erigir un convento de clarisas en Teruel. Este hecho se puede comprobar, por lo menos, desde el año 1350. La reina se encargó de informar por carta a los prohombres de Teruel y a Ramon Saera de su voluntad de fundar un monasterio de clarisas en la ciudad, pidiendo al mismo tiempo a sus destinatarios que por honor nuestra e servicio querades faer e treballar en aquestes affers secretament ${ }^{26}$, es decir tratar el asunto en secreto. Como procuradores, Leonor de Sicilia acreditó a Martín Martínez de Marcilla (Marziella) y Juan López de Santa $\mathrm{Cruz}^{27}$. Al parecer, no abandonó este proyecto en los años siguientes como se puede deducir de dos cartas posteriores. El ministro general de los franciscanos, Guillaume Farinier, otorgó a la reina el 12 de marzo de 1350 la facultad de trasladar a dos o más monjes de la provincia fran-

${ }^{25}$ El vicario arzobispal Johannes Boeti mandó el 31 de enero de 1407 al clero de la ciudad y del arciprestazgo de Teruel coleccionar donaciones para la reconstrucción de la iglesia de Santa Catalina ("ecclesia devota heremitana sancte Caterine, constructa in campo Celfe termini civitatis Turolii") y otorgó una indulgencia de 30 días, ADZ, RACO, vol. 6: 1407, 1408. Año 1407, f. 12r [1].

${ }^{26}$ ACA, Canc., Reg. 1563, f. 88r [2] a los prohombres de Teruel e ibidem, f. 88v [1] a Ramon Saera (Çaera), Zaragoza, 1350 mayo 7 . Tal vez hay que identificar el destinatario de la segunda carta con el jurista manresano que era abogado fiscal de la bailía y veguería de Manresa.

27 Ibidem, f. 88v [1] a Ramon Saera, Zaragoza, 1350 mayo 7: "Porque vos rogamos instantment que (...) querades (...) creer a los ditos Martín Martínez e Johan López de aquello que sobre las ditas cosas de nuestra part vos dirán et fer cerca aquellos, segunt de vos confiamos"; sobre el significado de las familias de los Martínez Marcilla véase F. López, Datación, pp. 20-24 y G. Navarro, Muñoces, pp. 734-750. 
ciscana de Aragón al monasterio de clarisas previo consenso con el ministro provincial. Estos frailes fueron enviados para que instruyeran a las monjas del lugar y administraran los sacramentos. Además, la reina podría trasladar monjas de otras partes de Aragón a este monasterio de clarisas cuya construcción había sido decretada por la reina como consta en la carta del ministro general. Sin embargo, el lugar donde se había proyectado este convento, no se describe en esta carta $^{28}$. Además, se documenta una orden de Leonor de Sicilia al Mestre Racional del 10 de julio de 1352. En ella la reina manda al destinatario incluir en las cuentas de su tesorero, Berenguer de Relat, los 3.400 sueldos jaqueses que le había mandado oralmente pagar a los prohombres de Teruel pro quibusdam nostris secretis negotiis peragendis ${ }^{29}$. Estos dos documentos no mencionan explícitamente el lugar del monasterio pero -considerando las dos cartas antes citadas del año 1350- cabría suponer que la licencia del ministro general franciscano y la orden de pago a Berenguer de Relat están conectadas con los planes de la construcción de Santa Clara de Teruel.

Los planes de la fundación se concretaron a mitad de los años sesenta del siglo XIV: el 13 de diciembre de 1366, Leonor de Sicilia mandó a su tesorero, Berenguer de Relat, pagar 800 sueldos jaqueses al pintor Lorenzo de Zaragoza por dos retablos. Uno de ellos estaba destinado al monasterio de las clarisas que iba a fundar la reina en Teruel ${ }^{30}$. El convento se puede documentar definitivamente en abril de 1367. Leonor de Sicilia escribió el 30 de este mes al colector del morabetín en Teruel, Pero Fernández de Aranda, mandándole a comprar edificios en la ciudad para el monasterio y refiriéndose a éste como recientemente fundado ${ }^{31}$. Del año de la fundación data también la donación

${ }^{28}$ La facultad por parte del ministro general está insertada en una carta de Leonor de Sicilia a Philippus de Castro Johannis, ACA, Canc., Reg. 1563, f. 146r [1], Perpignan, 1351 marzo 8 , donde se hace constar lo siguiente: "Eodem tenore concedo ut duos vel plures fratres iuxta vestre potentie gratum imperium seu mandatum in monasterio, quod ad honorem Dei et nostri ordinis vestra potentia devotissima edificare decrevit, possitis ponere pro servitiis dominarum et ministrandis ecclesiasticis sacramentis et dictum monasterium edificare et ibi sorores ponere de aliis monasteriis pro novis sororibus instruendis iuxta directionem et consilium provincialis ministri". La lectura de "pro servitiis dominarum" no está segura. Sobre Guillaume Farinier véase J. Dendorfer, R. Lützelschwab (eds.), Geschichte, p. 240.

${ }^{29}$ ACA, Canc., Reg. 1565, f. 34v [1], Lleida, 1352 julio 10. Precisamente aquellos volúmenes del fondo Mestre Racional que contienen estos años (núms. 461-463) han quedado ilegibles por un daño causado por el agua. De ahí que no se puedan precisar ni la fecha ni las circunstancias del pago.

${ }^{30}$ A. Rubió, Documents, vol. 1, n. ${ }^{\circ}$ 218, p. 213: "monasterio sororum Minorum quod noviter, dante Domino, fundare et hedificare intendimus in civitate Turolii".

31 ACA, Canc., Reg. 1576, f. 25r [2], Zaragoza, 1367 abril 30: "monasterii minorissarum quod noviter hedifficari facimus in dicta civitate"; de una forma semejante la donación del palacio del 29 de mayo de 1367, A. López, Documentos, p. 429: “damus et concedimus (...) monasterio et ecclesie sororum Minorissarum, quod et quam (...) Nos et illustris Alionora regina Aragonum (...) instituendum noviter providimus". Los edificios adecuados quedaron to- 
del palacio real de Teruel por parte de Pedro IV y su esposa. Con ella el monasterio se asienta en su ubicación definitiva, donde todavía hoy se encuentra. Con todo, en relación a la fundación se debe aclarar un lapsus cronológico. Según la opinión unánime de las crónicas, la entrada de las monjas tuvo lugar dos años después de la fundación, es decir, el 10 de junio de $1369^{32}$. La información más precisa nos la proporciona la Crónica de los jueces de Teruel. En ella se data la entrada de las monjas el día 4 de junio de 1369 y el comienzo de la clausura el 10 de junio del mismo año ${ }^{33}$. Ninguna de las crónicas explica esta laguna cronológica entre la fundación de Santa Clara y el inicio de la vida conventual. Además, tampoco se encuentra mencionado este hecho en los documentos coetáneos. Todo apunta a que se trata de un error en la datación. En el mismo párrafo en el que se informa de la fundación de Santa Clara y la entrada de las monjas, la Crónica de los jueces de Teruel se refiere a la vuelta de Enrique de Trastámara a Castilla y su gobierno paralelo al de Pedro I "el Cruel" (1350-1369) ${ }^{34}$. Como es sabido, estos acontecimientos tuvieron lugar en el año 1367. En cambio, la versión AHPT de la Crónica de los jueces de Teruel los data, en la mayoría de los casos, dos años después. El editor, Fernando López Rajadel, corrige consecuentemente la cronología. Está claro que la fundación del convento y la entrada de las clarisas ha de fecharse en el mismo año. Y por esa misma época hubo de tener lugar también la consagración del convento. En mayo de 1367, se pagaron 50 sueldos jaqueses al guardián de los franciscanos de Teruel, Sancho de Miza (Miça). Dicha cantidad se había pagado por orden de la reina al arzobispo de Zaragoza para obtener el derecho de sello del diploma de consagración ${ }^{35}$. La reconstrucción del palacio como monasterio se terminó probablemente en 1369 , cuya ceremonia inaugural se recuerda en las crónicas.

En el monasterio se establecieron algunas monjas que en 1367, antes de mediados del año, habían viajado de Zaragoza a Teruel. En concreto, se sabe que fueron la abadesa y cinco monjas más ${ }^{36}$. Las clarisas de Zaragoza

davía para construir: "In quoquidem palatio seu domibus regiis dictum monasterium et ecclesia construantur".

${ }^{32}$ F. Gonzaga, De origine, p. 710; L. Wadding, Annales, p. 220; J.A. de Hebrera, Chronica, p. 199.

33 Versión AHPT, F. López, Crónicas, p. 188. En cambio, J. Caruana, Una relación, p. 241 no comenta o corrige la cronología errónea.

${ }^{34}$ F. López, Crónicas, p. 188: "En esti año fue el rey don Anrich tornado a Castiello en su regno, et regnavan dos reyes, el rey don Pedro y el rey don Anrich en Castiella por gran daño della et con mala verdat ques en ella".

${ }_{35}$ M. Anglada, Els quatre llibres, p. 191: El pago se efectuó "per dret de segell de la carta de la consecració del monestir de les menoretes que la dita Senyora fa fer en la dita ciutat".

${ }^{36}$ F. Gonzaga, De origine, p. 710; comprobante para los gastos de viaje de la abadesa y de cinco monjas en ACA, ARP, MR, Volúmenes, Serie General, 489, f. 98r [1], s. 1., 1367 junio. 
cultivan la tradición de que en el convento de Teruel se habría fundado con monjas procedentes de su monasterio. No obstante, esta hipotesis verosímil no se puede comprobar con seguridad en las fuentes. Una de las monjas, Sancha Martínez de Pueyo, procedía de Huesca y viajó como muy tarde en junio de 1367 a Teruel, pasando también por Zaragoza ${ }^{37}$. En todo caso, el itinerario de las monjas demuestra al menos que en Santa Clara de Teruel se asentaron clarisas que provenían de Aragón central y septentrional. Aunque se desconoce la fecha exacta de la fundación del convento turolense, se puede datar a través de estos indicios en el período entre mediados de diciembre 1366 y finales de abril de $1367^{38}$. Nótese además que la entrada de las monjas tuvo lugar poco después, es decir, en la primavera o el verano de 1367. Por consiguiente, hay que descartar la existencia de un asentamiento anterior de clarisas a partir de los años 30 del siglo XIV fuera de las murallas de Teruel. En consecuencia, si la alusión a una fundación de los años treinta, de la que nos da cuenta Gonzaga, es un simple lapsus tipográfico o una referencia a un beaterio anterior que hubiera podido constituir el núcleo inicial de Santa Clara, es algo que no se puede resolver con la información que nos ofrecen las fuentes disponibles. Como se ha visto, entre los primeros testimonios en los que consta la voluntad de Leonor de Sicilia de fundar un monasterio de clarisas en Teruel y la realización de este proyecto, pasaron aproximadamente 15 años. Probablemente esta laguna temporal se pueda explicar en relación a los acontecimientos de los años cincuenta y sesenta, es decir, la expedición a Cerdeña y la Guerra de los dos Pedros, que habrían impedido la fundación del convento. En cualquier caso, pasaron aproximadamente 150 años entre la fundación del monasterio de la primera orden y su correspondiente femenino ${ }^{39}$. La cronología observada por Jill Webster, según la cual en la Corona de Aragón solían mediar tan solo algunas décadas entre la fundación de un monasterio franciscano y la de uno de clarisas, no es válida para Santa Clara de Terue ${ }^{40}$. Además, se trata en este caso de un establecimiento de clarisas muy tardío, de hecho, la fundación medieval más tardía en el propio reino de Aragón.

Acerca de la iniciativa de la fundación no se puede extraer información clara ni de las fuentes coetáneas ni de las posteriores. La cronística atribuyó la fundación, en parte, a Leonor de Sicilia y, en parte, a Leonor conjun-

${ }^{37}$ M. Anglada, Els quatre llibres, p. 212.

${ }^{38}$ O. Taravilla, Perfiles, p. 39-40 data el período posible entre febrero y diciembre de 1367 con base en los datos proveídos por la edición de M. Anglada, Els quatre llibres.

${ }^{39}$ El convento franciscano se fundó alrededor de 1220, véase J. Moorman, History, p. 72.

40 J. Webster, Els franciscans, p. 295. 
tamente con su esposo Pedro IV, pero en última instancia sobre todo al rey ${ }^{41}$. Sin embargo, aunque las fuentes documentales nombran a los dos monarcas por igual como fundadores, se debe atribuir esta iniciativa a la reina, como prueban los planes que se documentan ya poco tiempo después del inicio de su reinado. A esto se suma que hay que considerar la fundación del convento no como un hecho aislado sino contextualizarla en el marco de una estrategia general de fomentar Teruel por parte de Pedro IV. Debido a la lealtad que mostraron los habitantes de Teruel en el conflicto de las Uniones, el Ceremonioso había elevado la villa al rango de ciudad. Además, el rey impulsó la creación de una sede episcopal en la ciudad, tal y como les había prometido ya a los habitantes al cederles los privilegios municipales ${ }^{42}$. En este sentido, también intervino Leonor de Sicilia con su primera carta al papa Clemente VI, datada en noviembre de 1349, es decir, aproximadamente tres meses después de contraer matrimonio con Pedro $\mathrm{IV}^{43}$. Los reyes promocionaron conjuntamente y de mutuo acuerdo la ciudad de Teruel, que finalmente no pudo contar con la creación de la sede episcopal en la época del Ceremonioso. En general, la actual apariencia del edificio del convento no ofrece claves de representación de su fundadora o fundadores. Sin embargo, sí encontramos en el sobrio edificio un escudo siciliano en el que se muestra únicamente a Leonor o mejor dicho a la dinastía siciliana, conservando de esta forma la memoria de la fundadora ${ }^{44}$.

La fundación de Santa Clara se realizó sub invocatione beate Caterine virginis et martiris ${ }^{45}$, es decir, bajo la invocación de la santa Catalina, lo que hace plausible establecer una filiación con las clarisas de Zaragoza. No obstante, como la veneración de esta santa estaba muy extendida en Aragón, tampoco se puede confirmar con toda claridad la existencia de tal filiación desde la capital de este reino. Ya en el mismo año de la fundación, Santa Clara obtuvo una dotación de ingresos y privilegios por parte de los monarcas, de la que se encargó fundamentalmente Leonor de Sicilia. Antes y durante la

${ }^{41}$ J.A. de Hebrera, Chronica, p. 199. F. Gonzaga, De origine, p. 710 reconoce la petición de Leonor de Sicilia y le atribuye la institución de Santa Clara a Pedro IV. Tan solo dos versiones de la Crónica de los jueces de Teruel informan de la fundación del monasterio. Entre ellas, la versión A (Archivo Municipal de Teruel) nombra exclusivamente a Leonor, la versión AHPT, en cambio, a los dos monarcas, F. López, Crónicas, p. 188.

${ }^{42}$ A. López, Catálogo, doc. 120,pp. 70-71. El juez Pedro Muñoz de Godos había informado al concejo municipal el 26 de octubre 1347 de los planes del rey al tiempo que había pedido el respaldo de los prohombres a cargo del rey para hacer la correspondiente petición al Papa.

${ }^{43}$ ACA, Canc., Reg. 1563, f. 16v [1], [Valencia], 1349 noviembre [17]. Las instrucciones de Leonor de Sicilia al embajador Thomas de Marca exigen entre otras cosas: "Item que suplicha al Pare Sant de part de la dita senyora Reyna que vu[lla] donar bisbe en la ciutat de Terol, con lo senyor Rey li y haia moltes vegades suplicat et suplich encara de present et entena suplicar tro atorgat ho haia".

${ }_{44}$ Véase figura 1.

${ }^{45}$ ACA, Canc., Reg. 1581, f. 171v [1], Barcelona, 1373 junio 23. 
fundación del convento, en la primavera de 1367, ella instruyó al recaudador del morabetín en Teruel, Pero Fernández de Aranda, para que destinara los ingresos de hasta un máximo de unos 2.000 sueldos jaqueses a adquirir aquellos edificios que ella había mandado comprar para el monasterio que recientemente había hecho construir. Pocos días después aumentó con otra orden a Pero Fernández este importe en 1.000 sueldos $^{46}$. Poco después, el 29 de mayo de 1367 , los soberanos pusieron a disposición de las monjas el palacio real en la ciudad donde tomaron residencia las monjas. Esta donación se puede considerar, a falta del acta fundacional, como el momento decisivo para la institución de Santa Clara de Teruel. Pero en relación a ella, se hace necesario destacar una particularidad de este documento. Aunque fue expedido a nombre de Pedro IV, fue su esposa, Leonor de Sicilia, la que dio la orden para su elaboración. El rey se limitó simplemente a dar su visto bueno, tal y como lo atestigua la iussio en la entrada del registro correspondiente ${ }^{47}$.

Este modo de proceder ejemplifica de una manera muy evidente la influencia que la reina podía llegar a ejercer mediante la expedición de documentos a nombre de su esposo, incluso en fases de su reinado en las cuales ella no actuaba como lugarteniente. Mediante otro privilegio Pedro IV autorizó a las monjas importar vino a la ciudad en la cantidad que quisieran sin necesidad de pagar impuestos ${ }^{48}$. Además, el rey mandó a los prohombres a limpiar los alrededores del monasterio de prostitutas y mujeres de mala fama en general para mantener la reputación de las clarisas. Se prohibió a dichas mujeres bajo pena de 100 morabetines de oro que se asentaran cerca de Santa Cla$\mathrm{ra}^{49}$. Esta medida enfatizó el estatus del monasterio, que muy probablemente estaba pensado como modelo aristocrático destinado a la representación de

${ }^{46}$ ACA, Canc., Reg. 1576, f. 25r [2], Zaragoza, 1367 abril 30 e ibidem, f. 28v [2], Zaragoza, 1367 mayo 12. El monasterio se menciona como fundado recientemente: "quod noviter hedifficari facimus" y "quod noviter construi facimus" respectivamente.

${ }^{47} \mathrm{La}$ entrada del registro se encuentra en ACA, Canc., Reg. 914, f. 57v [1], Zaragoza, 1367 mayo 29 y se termina con la nota de la cancillería: "Domina Regina ex parte domini Regis mandavit michi, Petro de Gostemps. Vidit eam dominus Rex. Bernardus de Bonastre. Probata". En la edición A. López, Documentos, pp. 429-430 falta la nota, aunque debería haberse encontrado en el original que sirvió como base de la edición. En los privilegios se encuentra normalmente sobre o debajo de la plica, a veces también abiertamente por debajo del texto. Sobre las diferentes formas de la iussio (a base de ACA, Canc., Reg. 235, es decir Curie I de Jaime II) véase J. Trenchs, A. Aragó, Cancillerías, pp. 83-99.

${ }^{48}$ ACA, Canc., Reg. 914, f. 58r [2], Zaragoza, 1367 junio 15. Pedro IV mandó a los prohombres de Teruel a que las monjas "possint mittere vel mitti facere intra dictam civitatem vinum quantum eis vel ad opus dicti monasterii fuerit necessarium".

49 ACA, Canc., Reg. 914, f. 58r [1], Zaragoza, 1367 junio 16. Pedro IV prohibió a los prohombres que "alique meretrices publice vel secrete seu alie mulieres inhoneste conversationis seu male fame circumcirca dictum monasterium usque ad illas remotas partes, quas vos seu aliquis vestrum noveritis, nullo unquam tempore domiciliari possint seu etiam habitare". Pedro IV tomó a instancia del guardián de los franciscanos de Barbastro una medida semejante para 
la familia real. Así, probablemente, Santa Clara de Teruel no debió ejercer una función caritativa en contraste con otros monasterios de clarisas antes del establecimiento de la clausura estricta ${ }^{50}$. Al contrario, debió estar destinado exclusivamente a la memoria de sus fundadores. Mediante un tercer privilegio, Pedro IV permitió a las monjas hacerse con cuatro carruajes de madera diarios procedentes de los territorios de las ciudades de Teruel y Albarracín ${ }^{51}$. Finalmente, el Ceremonioso donó a las clarisas cinco cahíces (cafficia) de sal de las salinas de Arcos, donación que Leonor de Sicilia confirmó poco tiempo después $^{52}$. Las monjas también podían disfrutar de estos dos últimos ingresos sin pagar impuestos. Aun en el año de la fundación se nombró como primer procurador del convento a Pero Fernández de Aranda, el ya mencionado recaudador del morabetín de Teruel, que aparece además como juez de Teruel en el año 1348, lo que nos permite situarlo entre los grupos dirigentes de la ciu$\mathrm{dad}^{53}$. Por todos los motivos expuestos anteriormente, Santa Clara de Teruel parece haber gozado desde su fundación de un estatus privilegiado.

Todos los llamados privilegios del convento fueron expedidos por Pedro IV, lo que podría llevar a pensar en el poco interés de su esposa en la fundación turolense. Sin embargo, hay que matizar esta imagen. La autoría de las concesiones no se puede atribuir exclusivamente al rey sin tener en cuenta la participación de la reina. Un ejemplo de ello lo constituye la mencionada donación del palacio real. Otro caso semejante fue el nombramiento del procurador Pero Fernández de Aranda. Pedro IV le otorgó esta función a petición de la abadesa y del convento. Sin embargo, -tal y como consta en la iussiotambién en este caso el acta se elaboró por orden de la reina y el rey dio su visto bueno antes de expedirla ${ }^{54}$. Por lo tanto, también aquí habría que suponer una influencia determinante de la soberana en el nombramiento. Una carta posterior destinada al merino de Zaragoza, Domingo López Sarnés, confirma esta suposición. El rey le mandó el 30 de septiembre de 1368 seguir pagando a la abadesa la remuneración anual de 1.000 sueldos, dinero que ella ya había recibido antes de asumir esta función. Aunque Leonor de Sicilia mandó

el monasterio conminando igualmente una pena de 100 morabetines, solo que se formula aquel texto de una manera más explícita, véase J. Vincke, Documenta selecta, no ${ }^{\circ} 637$, pp. 485-486.

50 Sobre las funciones caritativas de las fundadoras de S. Antoni de Barcelona véase N. Jornet, El monestir, p. 86.

${ }^{51}$ ACA, Canc., Reg. 914, f. 97v [1], Zaragoza, 1367 agosto 10.

${ }_{52}$ Privilegio de Pedro IV en ACA, Canc., Reg. 914, f. 113r [4], Zaragoza, 1367 septiembre 3 y la confirmación de Leonor de Sicilia en ACA, Canc., Reg. 1575, f. 58v [1], Barcelona, 1367 octubre 20.

53 J. Caruana, Una relación, p. 237.

54 ACA, Canc., Reg. 914, f. 128v [1], Zaragoza, 1367 septiembre 20: "Domina Regina ex parte domini Regis mandavit michi, Petro de Gostemps. Vidit eam dominus Rex. Michael de Bordello". 
expedir dicho documento, aquí no aparece el visto bueno del rey ${ }^{55}$. Se podría objetar que las iussiones solo reproducen la transmisión de la voluntad real y no tienen valor propio. No obstante, aparte de las fases en las que actuaba como lugarteniente, la reina aparece solamente en casos muy concretos en las iussiones de los registros reales y, por consiguiente, estos testimonios demuestran más bien una participación intensa de Leonor de Sicilia en la elaboración de estas donaciones y su interés particular en la fundación. Como se trata de referencias indirectas, la participación de la reina en los inicios espléndidos de Santa Clara de Teruel parece disminuir en importancia frente al papel de su esposo Pedro IV, por lo menos en relación a los privilegios otorgados al convento.

Esta imagen cambia en los años siguientes en los que predominan las donaciones por parte de Leonor de Sicilia. En el año 1368 ella misma donó al monasterio ingresos anuales procedentes de un censo de la ciudad de Teruel por un valor correspondiente a 2.000 sueldos jaqueses que había comprado a sus ciudadanos y que tenían que pagarse en la fiesta del arcángel Miguel ${ }^{56}$. También en este documento hay que destacar una particularidad. El privilegio incluye una arenga $\mathrm{o}$, al menos, un párrafo de un contenido general semejante, explicando los motivos de la reina para la donación. Su inclusión constituye una excepción entre los documentos de Leonor de Sicilia. En él se explica que, mediante la fundación de Santa Clara de Teruel, Leonor de Sicilia se alinea con la venerable tradición de los reyes de Aragón, que habrían apoyado a la Iglesia desde sus inicios construyendo iglesias y monasterios ${ }^{57}$. Además, la reina considera necesario dar gracias por su posición suprema entre las reinas del mundo y por los beneficios recibidos de $\operatorname{Dios}^{58}$. Mediante la inserción de este párrafo se pone de relieve la importancia de la donación y también del destinatario. Cinco años después, se aumentaron los ingresos del monasterio en 2.000 sueldos barceloneses gracias a un censo procedente de las aldeas de

55 ACA, Canc., Reg. 1220, f. 67v [1], Barcelona, 1368 septiembre 30: "Domina Regina ex parte domini Regis mandavit michi, Guillelmo Oliverii”.

56 ACA, Canc., Reg. 1577, f. 106v [1], Barcelona, 1368 diciembre 10.

${ }^{57}$ Ibidem, "Pateat universis quod nos, Alienora etc., recolimus sicuti in publicam notionem deducitur qualiter ab exordio nascentis ecclesie in regno Aragonum progenitorum nostrorum Regum Aragonum digne recolenda prioritas propter divini cultos augmentum costruxit (sic!) ecclesias et monasteria, que amplis dotavit redditibus et privilegiis communivit".

${ }^{58}$ Ibidem, "Contemplamur etiam ut, quo divina dextera inter ceteras Reginas mundi nostrum in sublimi posuit solium, eo per officiose gratitudinis debitum nostra devotio sibi solvat munera gratiarum, ne pro tantis collatis nobis ab alto beneficiis per lapsum memorie ingrate iudicemur, profecto eius scilicet redemptoris nostri rememorantes beneficia, nec valentes sibi ut tenemur et obtamus aliis secularibus ingruentibus negotiis prepedite obsequiosum reddere famulatum". 
Teruel $^{59}$. Ambos censos se compraron por la cantidad de 20.000 sueldos y no eran permanentes, ya que los vendedores tenían la opción de readquirirlos. Si se daba el caso de una retroventa por parte de la ciudad o las aldeas de Teruel, las monjas tenían que usar el importe para la adquisición de una renta similar. Otra compra de una renta por parte de Leonor de Sicilia se menciona en su codicilo, según el cual, ella había comprado un censo de 500 sueldos jaqueses de Mateo Sánchez de Cutanda de Teruel ${ }^{60}$. La compra de este censo no se encuentra en los registros de Leonor de Sicilia. Si comparamos las donaciones de los dos monarcas en su conjunto, se puede constatar que la reina abasteció el monasterio de dotaciones pecuniarias de mayor importancia.

Además, Santa Clara de Teruel obtuvo a instancias de Leonor de Sicilia en el año 1371 algunos privilegios por parte de la Curia Romana. Entre ellos, se encuentran la licencia de usar un báculo (baculum pastoralis) ${ }^{61}$ y el derecho a tener un cementerio propio comparable al de otros monasterios de clarisas $^{62}$. Más allá de esto, Leonor de Sicilia obtuvo la licencia papal para escuchar la misa en compañía de dos monjas clarisas. Estas dos acompañantes podían explicarle detalladamente a la reina las necesidades de la orden ${ }^{63}$. Este privilegio no está explícitamente relacionado con Santa Clara de Teruel. Sin embargo, como se expidió el mismo día que el de usar un báculo, se podría suponer una referencia implícita a la abadía turolense. Además, el papa Gregorio XI mandó, a instancias de la reina, al arzobispo de Zaragoza, Lope Fernández de Luna, asignar ingresos de 100 libras de Tours al convento de Santa Clara procedentes de los beneficios de su diócesis ${ }^{64}$. El metropolitano cumplió esta orden y les asignó a las clarisas ingresos de los arciprestazgos de Teruel y Daroca y de la iglesia de Mora ${ }^{65}$. En general, también la provisión generosa del convento con privilegios papales fue impulsada por la misma fundadora aunque esta era menos amplia que la dotación atribuida por la casa real.

${ }^{59}$ ACA, Canc., Reg. 1581, f. 171v [1], Barcelona, 1373 junio 23.

60 ACA, Canc., Reg. 1537, f. 156v [1], Barcelona, 1374 junio 12, véase f. 168r: "assignavimus et dedimus (...) illos quingentos solidos jaccenses annuales et rendales, quos pridem emimus a Matheo Sanccii de Cutanda, cive Turolii, pretio sex milium solidorum jaccensium cum laudimio et faticha et alio emphiteotico iure qui recipiuntur super diversis possessionibus, que sunt in orta dicte civitatis".

${ }^{61} \mathrm{BF}, \mathrm{n}^{\circ} 1121$, J. Vincke, Documenta selecta, $\mathrm{n} .^{\circ}$ 632, Avignon, 1371 mayo 2.

${ }^{62}$ A. López, Documentos, pp. 430-431, Villeneuve, 1371 julio 24.

${ }^{63} \mathrm{BF} \mathrm{n}^{\circ}{ }^{\circ} 1134$, Villeneuve-d'Avignon, 1371 julio 24. El BF solamente imprime el regesto y reproduce la inscripción y la datación. La tradición manuscrita se encuentra en ASV, Reg. Aven. 173, f. $475 \mathrm{v}$.

${ }^{64}$ Regesto en BF, ${ }^{\circ} 1155$, Avignon, 1371 noviembre 20.

${ }^{65}$ Notificación a la abadesa María Sánchez de Antillón, ACA, Canc., Reg. 1582, f. 84r [1], Barcelona, 1374 febrero 27. 
Aparte de estas contribuciones regulares a la economía del monasterio, la reina donó sucesivamente una serie de contribuciones individuales. Así, por ejemplo, se concedieron a Santa Clara bienes confiscados en procesos judiciales como las existencias de cereales (blat) y un mulo negro de Alí Maruhán y Abdalla Alfaquí, dos sarracenos de Teruel acusados de homicidio ${ }^{66}$. A partir de 1368, Leonor pagó anualmente en la segunda mitad del año por lo menos 1.000 sueldos jaqueses para el sustento del monasterio: a ops de la provisió sua del dit monestir ${ }^{67}$. Llama la atención el hecho de que todos estos importes se pagaran de forma muy rápida. Los pagos se realizaron, tal y como se puede comprobar en los libros ordinarios del Mestre Racional, dentro de un período máximo de cuatro meses y a veces en el mismo mes en el que se dio la orden de pago ${ }^{68}$. Es de destacar esta rapidez, ya que, en otros casos, los destinatarios de pagos podían llegar a esperar hasta años después de que se hubiera dado la orden por parte del soberano hasta la realización por parte del Mestre Racional. Si consideramos este hecho como algo significativo para valorar la importancia de Santa Clara de Teruel, está claro que fue una prioridad para Leonor de Sicilia. Aparte de los privilegios, la reina contribuyó de manera decisiva a la consolidación del monasterio con estos pagos regulares. En total, los pagos anuales durante la vida de la fundadora suman 6.500 sueldos jaqueses. Una excepción la constituye el año 1372, en el cual no se registra ninguna donación para el sustento del convento. Sin embargo, en este año se pagaron dos veces 1.000 sueldos jaqueses para la construcción de un aljibe (in constructione cuiusdam aljuppi seu çaffaregii) ${ }^{69}$. Entre 1369 y 1375, es decir, hasta la muerte de Leonor de Sicilia, no constan privilegios o donaciones por parte de Pedro IV. Tan solo figuran los esfuerzos de Leonor por mejorar la situación material del monasterio. Todos los certificados expedidos después del año fundacional fueron elaborados o bien por parte de la propia reina o bien a instancia suya. En comparación con el importante papel que aparentemente habría tenido el rey en el primer año del convento, Leonor de Sicilia destaca claramente como su principal promotora posteriormente. Santa Clara pudo disponer gracias a las donaciones de la reina de ingresos regulares considerables. En menor medida se pueden probar pagos periódicos o irregulares que

${ }^{66}$ ACA, Canc., Reg. 1580, f. 9r [1] así como [2], los dos datan de Valencia, 1371 mayo 30.

${ }^{67}$ ACA, ARP, MR, Volúmenes, Serie General, 492,f. 109v [1], s. 1., 1368 diciembre.

${ }^{68}$ En noviembre de 1371 se efectuó un pago de 1.500 sueldos jaqueses según una orden de pago del 13 del mismo mes con una carta que no se conserva, véase ACA, ARP, MR, Volúmenes, Serie General, 498, f. 92v [2] donde se menciona la carta de Leonor de Sicilia. Por consiguiente, el pago se realizó en un máximo de 17 días.

${ }^{69}$ La cita se encuentra en ACA, Canc., Reg. 1583, f. 108r [1], Barcelona, 1374 mayo 12 y los pagos en ACA, ARP, MR, Volúmenes, Serie General, 500, f. 56r [1], s. 1., 1372 julio e ibidem f. 117r [2], s. 1., 1372 diciembre. 
sumados, sin embargo, llegan a cantidades significativas. Se trata de los ya mencionados gastos de viaje de las monjas, la construcción del aljibe, el retablo creado por Lorenzo de Zaragoza y también algunos libros. Si se resumen las contribuciones pecuniarias por parte de la casa real a Santa Clara de Teruel, constan, sobre todo, ingresos regulares otorgados por parte de su fundadora.

Como documentos clave para la dotación de Santa Clara se pueden considerar el testamento y el codicilo de Leonor de Sicilia del 12 de junio de 1374. En ellos se fijaron los ingresos anuales del monasterio a 5.000 sueldos jaqueses ${ }^{70}$. Como las rentas que había transferido antes al monasterio no eran fijas, el codicilo estableció su carácter permanente. Para poder realizar esta disposición, Leonor de Sicilia legó a las clarisas el considerable importe de 40.000 sueldos jaqueses. Además de esto, les dejó otros 20.000 sueldos para las obras del monasterio que, al parecer, no habían acabado en aquel momento. Este legado constituye, en comparación con los demás beneficiarios del testamento de la reina, el de mayor importe. El heredero principal, el infante Martín, confirmó las disposiciones testamentarias ya en 1375 con la aprobación por parte de Pedro IV ${ }^{71}$. Para cumplir con ellas, Martín atribuyó al monasterio ingresos de un censo de sus bienes en Xèrica. Aparte de ser la mayor donación por parte de los monarcas aragoneses, este legado fue al mismo tiempo la última de estas donaciones. Con posterioridad a ella el infante Juan solo confirmó los privilegios. Durante su estancia en Teruel, en la cual probablemente medió entre las familias de los Muñoz y Marcilla ${ }^{72}$, el 1 de diciembre de 1382, Juan confirmó a Santa Clara la licencia para importar vino a la ciudad ${ }^{73}$, el derecho a cortar madera en Teruel y Albarracín ${ }^{74}$ y además los ingresos de las salinas de $\operatorname{Arcos}^{75}$. No se ha podido localizar la confirmación del palacio real por parte del rey Martín I que menciona Juan Gaspar Sánchez Muñoz en su lista de los diplomas reales existentes en el monasterio ${ }^{76}$. Como los datos son correctos en los demás casos, resulta extraño que no se encuentre este privilegio en los registros reales. Tal vez no se registró, pero este hecho en un diploma de esta categoría sería sumamente excepcional. En cambio, no

70 ACA, Canc., Reg. 1537, f. 139r [1] (testamento) e ibidem, f. 156v [1] (codicilo, legado para Santa Clara en ff. $165 \mathrm{v}-169 \mathrm{v}$ ). Este volumen de registro está en un estado precario. Una copia bien conservada del codicilo se encuentra en ACA, Canc., Varia de Cancillería, $\mathrm{n}^{\circ} 22$, ff. $133 \mathrm{r}-148 \mathrm{v}$.

${ }^{71}$ ACA, Canc., Reg. 2064, f. 152r [1], Barcelona, 1375 agosto 24. Aquí se encuentra el texto insertado del codicilo.

${ }^{72}$ G. Navarro, Muñoces, pp. 738; F. López, Crónica, p. 188.

${ }_{73}$ ACA, Canc., Reg. 1686, f. 232r [1].

${ }^{74}$ ACA, Canc., Reg. 1687, f. 47v [1].

${ }^{75}$ ACA, Canc., Reg. 1687, f. 48v [1].

${ }^{76}$ G. Sánchez, Diario, p. 74. 
están documentadas las confirmaciones de los censos y probablemente tampoco eran necesarias. Pero, por lo menos, se atestigua su pago al monasterio a través de recibos expedidos por la abadesa al procurador de la ciudad y de la comunidad de aldeas de Teruel.

No obstante, la transferencia y el usufructo de los ingresos fijados por las donaciones no estuvieron exentos de problemas, que habían comenzado ya en vida de Leonor de Sicilia. La asignación de los ingresos de los beneficios de las iglesias de Teruel, Daroca y Mora se realizó con la oposición del cabildo catedralicio de Zaragoza. Este se opuso a su aprobación poco después de la elaboración de la bula papal por parte de Gregorio XI en $1372^{77}$. Esta oposición solo consiguió aplazar la ejecución de la orden papal, pero no logró evitarla. Aunque no se puede concretar el momento exacto para aclarar este asunto, sí se puede determinar aproximadamente. Un año y medio después, el 18 de febrero de 1374, Leonor de Sicilia dio las gracias al arzobispo Lope Fernández de Luna por haber arreglado algunos asuntos en torno a Santa Clara de Teruel. La reina prometió literalmente demostrarle su gratitud por estas obras $^{78}$. Aunque no se mencionan explícitamente los beneficios, se puede atisbar la relación que debía de haber. Pero con su transferencia los problemas no finalizaron. A inicios del siglo XV, los beneficiarios en las iglesias se opusieron a pagar los importes debidos a las clarisas ${ }^{79}$. Ya en mayo de 1402 el arzobispo de Zaragoza, García Fernández de Heredia, citó a los curas en cuestión al tribunal arzobispal para resolver el litigio entre ellos y el convento ${ }^{80}$. Pero al menos el cura de Mora no cumplió esta orden y el arzobispo tuvo que citarlo de nuevo poco tiempo después ${ }^{81}$. La situación se agravó hasta llegar a una demanda de las monjas en la Curia Romana y a la intervención del rey Martín I. El 21 de enero de 1407, el monarca volvió a remitir la queja de las clarisas al arzobispo de Zaragoza, juez responsable de la solución del asunto ${ }^{82}$. Como un año más tarde el litigio seguía sin solucionarse, el rey se dirigió al papa Benedicto XIII y le pidió, con motivo de la carestía que sufría Santa Clara y de la necesidad de protección que sentían las monjas, que decidiera urgentemente a favor de ellas ${ }^{83}$. Cabe pensar que la intervención real logró la reacción por

77 ACA, Canc., Reg. 1581, f. 43r [1], Barcelona, 1372 agosto 16.

78 ACA, Canc., Reg. 1582, f. 82v [1], Barcelona, 1374 febrero 18: "Nos vos haurem en nostra gràcia e amor e açò us mostrarem per obra".

79 V.J. Webster, Franciscans, p. 328.

${ }^{80}$ ADZ, RACO, vol. 4: 1402, 1404. Año 1402, f. 101r [1], Valderrobres, 1402 mayo 23.

${ }^{81}$ ADZ, RACO, vol. 4: 1402, 1404. Año 1402, f. 123v [1], Valderrobres, 1402 julio 31.

82 ACA, Canc., Reg. 2180, f. 107v [1], Valencia, 1407 enero 21.

${ }^{83}$ ACA, Canc., Reg. 2187, f. 6r [1], Barcelona, 1408 noviembre 22: "Cupientes idcirco litibus, quibus easdem moniales dicto pretextu in Romana Curia nunc vexantur per possessores beneficiorum superius expressorum, finem imponi, Sanctitas vestra humiliter supplicamus, quatenus nostra 
parte de la Curia Romana, que nombró al cardenal Martín de Zalva de Santa Lucina como legado para mediar en el litigio. El legado ya había dictado su sentencia en 1383 y el arzobispo la confirmó el 6 de febrero de $1407^{84}$. No se conoce ningún otro documento posterior a la confirmación del arzobispo, la cual se considera como el punto y final del litigio".

La toma de posesión de los censos legados por Leonor de Sicilia a las monjas tampoco estuvo exenta de problemas. Las dificultades comenzaron poco tiempo después de la muerte de la reina. Para cumplir el testamento, su heredero Martín atribuyó el 24 de agosto de 1375 un censo de 4.000 sueldos jaqueses de la ciudad y la tenencia (tenentia) de Xèrica a las monjas de Santa Clara ${ }^{85}$. Los prohombres de Xèrica no cumplieron la orden de pago en seguida ${ }^{86}$. La situación no se aclaró, por lo menos, hasta inicios de 1376. Para obtener la aprobación de los prohombres, el infante Martín envió al camarero de su esposa, Bonafonat de Sentfeliu ${ }^{87}$. Este había sido desde octubre de 1371 caballerizo (cavalleriç) de Leonor de Sicilia ${ }^{88}$ y posiblemente conocía las condiciones particulares de Santa Clara de Teruel, aunque no existan pruebas anteriores que lo relacionen con el monasterio. La intervención del infante y el envío del camarero parecen haber solucionado la situación, ya que no se documentan otras medidas a este respecto. Una prueba indirecta de las dificultades por las que estaba pasando el convento de Santa Clara la proporciona la confirmación del infante Juan que autorizaba al convento a cortar madera. En ella se añade, a petición de la abadesa y de las monjas, un párrafo que prescribe una multa de 100 morabetines de oro a los infractores de este derecho. Dos tercios de la multa tenían que pagarse al tesoro real y un tercio a la justicia de Teruel o Albarracín ${ }^{89}$. Aunque no existan pruebas directas en este

honore respectu intuituque paupertatis et sexus debilis monialium premissarum dignetur causas easdem (...) resinuere easque breviter sine debito terminare".

${ }^{84}$ A. López, Convento, nº 2, p. 442-446.

85 La confirmación de las cláusulas testamentarias en ACA, Canc., Reg. 2064, f. 152r [1], Barcelona, 1375 agosto 24. La orden de pago a los habitantes de Xèrica y la notificación al protonotario Jaume de Castelló en ACA, Canc., Reg. 2099 f. 63 [1], Barcelona, 1375 septiembre 1 e ibidem, f. 67r [2], Barcelona, 1375 septiembre 22.

${ }^{86}$ ACA, Canc., Reg. 2099, f. 91v [1], Barcelona, 1375 noviembre 22.

87 Notificación sobre el envío a la abadesa y las monjas de Santa Clara, ACA, Canc., Reg. 2099, f. 149v [1], y Pero Fernández de Aranda, ibidem, f. 149v [2]; las dos cartas datan de Barcelona, 1376 febrero 21.

${ }^{88}$ ACA, Canc., Reg. 1564, f. 56r [2].

${ }^{89}$ ACA, Canc., Reg. 1687, f. 47v [1]: "Idcirco ad humilem supplicationem sive instantiam dictarum abbatisse et conventus propterea nobis factam per presentem cartam nostram omnia et singula in dicta concessione regia contenta dictis abbatisse et conventui, prout hactenus melius use fuerunt, totaliter confirmamus, mandantes per hanc eandem gerenti vices pro nobis in regno Aragonum, iudicibus, iustitiis et iuratis ac probis hominibus dictarum civitatuum Turolii et Albarrazini aliisque universis et singulis officialibus et subditis dicti domini Regis atque nostris 
sentido, habría que interpretar la inserción de este pasaje en el acta como un indicio de que esta indicación había resultado insuficiente. De modo similar se puede valorar el salvoconducto del virrey Gil Rodríguez de Lihori, quien el 6 de mayo de 1400 puso bajo su protección a la abadesa Elvira López de Arbre, a las monjas y a los procuradores de Santa Clara ${ }^{90}$. En este punto se incluyó aun una multa de 1.000 morabetines de oro. Tampoco en este documento se señalan acontecimientos concretos, pero debido a lo elevado de la multa cabe suponer las grandes dificultades por las que estaba pasando el monasterio. Tal vez pueda relacionarse dicho salvoconducto con la querella entre las estirpes de los Marcillas y los Muñoces, que estaba desarrollándose en aquella época y que concluyó con una tregua en $1407^{91}$. En suma, los problemas mencionados apuntan a un comienzo bastante difícil para Santa Clara de Teruel, por lo menos, a nivel económico.

Aparte de las dificultades mencionadas que tuvieron lugar más bien a un nivel institucional, también hubo intrusiones directas contra el monasterio mismo. En 1445 les habían robado a las monjas, entre otras cosas, un anillo de oro, que les había regalado Leonor de Sicilia, y el báculo de la misma reina. Debido a ello, la reina María de Castilla mandó el 3 de marzo de 1445 al presunto ladrón, Juan Celi de Teruel, bajo amenaza de tomar medidas de fuerza, que restituyera a las monjas todos los bienes robados ${ }^{92}$. Al parecer, no era seguro que Juan fuera a cumplir esta orden, porque justo un día antes María de Castilla había ordenado a todos los oficiales reales de la ciudad confiscar todos los objetos de la casa de dicho Juan ${ }^{93}$. Aunque no se conozcan más dificultades aparte del caso mencionado, podrían suponerse otros casos de delincuencia hacia el monasterio, si bien debieron tratarse de casos aislados. Los demás aspectos relacionados con la historia inicial de Santa Clara no se pueden trazar con la misma precisión que la dotación y los problemas referentes a ella.

Por ejemplo, casi no se atestiguan contactos directos entre la casa real y las monjas o intervenciones personales por parte de los soberanos relacionadas con los asuntos del convento. En un caso concreto, los reyes Juan I y Martín I

vel dictorum officialium locatenentibus presentibus et futuris sub pena centum morabatinorum auri a bonis cuiuslibet contrafacientium irremissibiliter habendorum erarioque regio sive nostro pro duabus partibus et pro reliqua iudici dicte civitatis Turolii vel Albarrazini pro exequtione fienda applicandorum, quatenus concessionem sive gratiam regiam preinsertam, prout use hactenus, ut premittitur, extiterunt necnon et presentem confirmationem nostram ducalem firmam habeant, teneant et observent et non contrafaciant sive veniant seu aliquem contrafacere vel venire permittant aliqua ratione".

90 A. López, Convento, ${ }^{\circ}$ 1, p. 442-443.

${ }^{91}$ F. López, Datación, pp. 105-110.

${ }_{92}$ M. García, El entorno, pp. 349-350; J. Webster, Deu documents, n. ${ }^{\circ}$ 9, p. 745-746.

93 ACA, Canc., Reg. 3230, f. 12r [2], Valencia, 1445 marzo 2. 
intercedieron en favor de una clarisa que quería mudarse de Teruel a Xàtiva ${ }^{94}$. La monja, sor Clara de Calatayud, estaba al principio en Xàtiva y tenía la intención de cambiar de lugar e irse a València para estar más cerca de su familia. Pese a un permiso por parte del Papa y los superiores de la orden, el convento de València se negó a recibir a sor Clara. No obstante, ella se había trasladado ya a València y vivía ya con su familia, es decir, entre personas laicas. Para evitar un escándalo mayor, el rey Juan I pidió el 7 de agosto de 1393 al convento de Xàtiva aceptar de nuevo a Clara en su seno. Al parecer este asunto no se pudo arreglar, ya que cuatro años más tarde sor Clara de Calatayud se hallaba en Santa Clara de Teruel. Como no aguantaba la crudeza del clima -tal y como lo explica Martín I en su carta a la abadesa de Xàtiva y al ministro provincial de Aragón- no se sentía en condiciones de cumplir con sus obligaciones espirituales, como le correspondía en calidad de monja y como le hubiera gustado. La disputa en torno a sor Clara de Calatayud se prolongó al menos cuatro años, según testimonian cartas de los años 1393 y 1397. Este caso da una idea, por un lado, del margen de acción que tenían los monasterios particulares y, por otro, de la vida individual de una monja. Se podría poner en cuestión su justificación con el argumento de la dureza del clima en Teruel, tal como se explica en la carta de Martín I y que esta hubiese sido la razón principal para el cambio deseado por sor Clara. Más bien, cabría pensar que quería estar más cerca de su familia o de su tierra natal, como se menciona en la carta de Martín I al ministro provincial, puesto que quería regresar al monasterio de las clarisas de Xàtiva, sobre todo a la ciudad, a qua suum originem traxit ${ }^{95}$. Solo después de haber aludido a esta razón, se enumera el clima como impedimento. Además, el trasfondo familiar enlaza los dos acontecimientos de modo tal que podría ser considerado como motivo principal para el deseado cambio de lugar.

Sor Clara residió solo temporalmente en Teruel y además evidencia de una manera muy periférica Santa Clara, su estructura social y sus problemas. Se trata de un caso particular, pero, aunque en general las fuentes no permiten reconstruir la composición personal y la vida social del monasterio, sí se pueden trazar algunas líneas relacionadas con estos aspectos. Ya desde la fundación se dispuso la ocupación permanente del convento por un numero de monjas cuya cifra exacta no es posible fijar ${ }^{96}$. Las fuentes conservadas de la fase anterior a 1375 tan solo permiten determinar un número aproximado

\footnotetext{
${ }^{94}$ V.J. Webster, Els franciscans, pp. 323-324.

${ }_{95}$ ACA, Canc., Reg. 2169, f. 42v [2], Sent Feliu de Llobregat, 1397 agosto 31.

${ }^{96}$ En la donación de 2.000 sueldos jaqueses de 1368, Leonor de Sicilia recuerda la disposición sobre la residencia permanente en el monasterio según el acta fundacional, ACA, Canc., Reg. 1577, f. 106v [1], Barcelona, 1368 diciembre 10: "in quo certum numerum sororum continue esse decrevimus".
} 
de residentes. Según el codicilo de Leonor de Sicilia debían residir unas 20 hermanas y el número mínimo debía ser de $15^{97}$. Siguiendo estos datos normativos, el número de 40 residentes del que informa Gonzaga resulta -por lo menos en el momento de la fundación y en el siglo XIV-improbable y debe referirse a una época posterior ${ }^{98}$. Aun en el momento más álgido, se trataba de un convento relativamente pequeño que abarcaba solo un tercio del tamaño de fundaciones más grandes como la de Santa Maria de Pedralbes ${ }^{99}$. Durante la vida de Leonor de Sicilia, Santa Clara de Teruel muy probablemente no llegó a 20 clarisas. En el año de la fundación se pueden calcular, aparte de la abadesa, aproximadamente 6 monjas. La primera abadesa María Sánchez de Antillón estaba antes de la fundación en estrecho contacto con la corte real, ya que antes de llegar a ser abadesa había recibido regularmente pagos para su vestimenta ${ }^{100}$. Sabemos que una de las primeras residentes viajó de Huesca, pasando por Zaragoza, a Teruel; sin embargo, no está claro el origen exacto de las demás monjas ${ }^{101}$. La llegada de las monjas en este año refuta además, como hemos visto, la hipótesis de un asentamiento anterior de las clarisas en Teruel. El número de las hermanas apenas cambió, ya que poco tiempo después, en el año 1371, vivían aparentemente, sin contar con la abadesa, tan solo seis monjas ${ }^{102}$. En conclusión, las fuentes conocidas ofrecen solamente indicios muy fragmentarios sobre la composición personal de Santa Clara. Asimismo, la serie de las abadesas solo se puede reconstruir con grandes lagunas. Para el período entre la fundación y el año 1600 se documentan tan solo nueve nombres y cuatro de ellos en el Diario de Juan Gaspar Sánchez Muñoz. Cinco de las abadesas se mencionan una sola vez en las fuentes ${ }^{103}$. Con mucha cautela

${ }^{97}$ ACA, Canc., Reg. 1537, f. 156v [1], v. f. 166v: "Declarantes et volentes, quod dicta abbatissa et eius conventus continue teneant et tenere habeant in dicto suo monasterio dictas viginti vel saltem XV sorores".

${ }_{98}$ F. Gonzaga, Origine, p. 710: "conuentus, qui \& a 40 Clarissis sororibus inhabitur".

99 J. Webster, Franciscans, p. 310, 321 con otros ejemplos como Valencia y Palma de Mallorca.

${ }^{100}$ ACA, Canc., Reg. 1220, f. 67v [1], Barcelona, 1368 septiembre 30.

101 Para el mes de junio de 1367 se documenta en los libros de cuentas que se conservan en el Arxiu Capitular de Barcelona el pago del alquiler de aquellos animales de montar con los cuales la abadesa y cinco hermanas viajaron en compañía del custodi dels frares menors de la Custòdia d'Aragó a Teruel. Sancha Martínez de Pueyo viajó en el mismo año de Huesca a Teruel para cuyo viaje Leonor de Sicilia mandó pagar también el alquiler de los animales de silla, M. Anglada, Els quatre llibres, pp. 206 y 212. Sancha Martínez de Pueyo está atestiguada en Huesca en 1359 y 1365, véase A. Ubieto, Documentos, doc. 107 (1359), p. 675-676 y doc. 111 (1365), p. 680.

102 ACA, ARP, MR, Volúmenes, Serie General, 498, f. 92v [2], 1371 noviembre [después del 13]. Se trata del pago de 1.500 sueldos jaqueses de los cuales 500 estaban destinados para la vestimenta de las hermanas: "per vestiari de la dita abadessa e de VI monges del dit convent del dit any present".

${ }^{103}$ Véase tabla 1 
se puede establecer la hipótesis de que los nombres de las abadesas testimoniadas en las fuentes muestran un interés de la aristocracia local por Santa Clara de Teruel. A inicios del siglo XVI siguió a Leonor Sánchez Muñoz, tía del cronista turolense, Isabel Garcés ${ }^{104}$. La última tal vez pueda relacionarse con la segunda rama de la familia de los Martínez ${ }^{105}$. Menos testimonios aun se encuentran de las otras monjas. Los documentos dejan constancia de sus nombres solo en casos aislados, al igual que el Diario turolense. Al parecer, se encuentra una lista completa de las monjas en la donación de un terreno por Juan Gaspar Sánchez Muñoz en el año 1533 que tuvo lugar en la sala capitular del monasterio y a la cual todas las monjas asistieron ${ }^{106}$. Las clarisas no eran las únicas residentes del convento. También vivían hermanas legas en Santa Clara tal y como se puede deducir de las donaciones de los censos por parte de Leonor de Sicilia en las que se mencionaba la obligación de la oración. Pero de estas últimas no conservamos ningún nombre. No se conoce a otras personas residentes en el monasterio, aunque se sabe que debieron existir. Leonor de Sicilia donó a la abadesa y a las monjas en 1367 una esclava, la conversa María. Esta había sido esclavizada porque, antes de su bautizo, había tenido contactos sexuales con cristianos ${ }^{107}$. Se trata del único caso conocido en que el convento obtuvo una esclava. Sin embargo, no debe haberse tratado de una excepción y es probable que el convento hubiera tenido otros esclavos, como por ejemplo Sant Antoni de Barcelona ${ }^{108}$.

Los procuradores de Santa Clara se conocen aun menos que las abadesas. Las fuentes los mencionan solo de vez en cuando y frecuentemente hacen caso omiso de ello. El codicilo de Leonor de Sicilia encargó a dos curas seglares y a dos scolares la cura de las almas de las clarisas. Estos clérigos también estaban obligados a residir en el monasterio y como recompensa por sus servicios recibían por parte del monasterio anualmente 300 y 100 sueldos respectivamente. Además, no debían obtener otros beneficios bajo pena de perder su posición en Santa Clara de Teruel. Los beneficios vacantes tenían que cubrirse en seguida y la abadesa tenía -según la disposición testamentaria de Leonor de Sicilia- el patronato ${ }^{109}$. La dotación de los beneficios era considerable; así, por ejemplo, los frailes encargados de la cura de almas en Santa Maria de Pedralbes recibían, aparte de una ración diaria de pan y vino, una

104 G. Sánchez, Diario, pp. 10-11, 25.

105 Sobre el origen común de las dos ramas v. G. Navarro, Muñoces, p. 744.

106 AHPT, Concejo de Teruel, Carpeta Verde, 10/195, Teruel, 1533 febrero 17.

107 ACA, Canc., Reg. 1576, f. 56v [1], Zaragoza, 1367 agosto 11.

108 N. Jornet, Monestir, p. 248-249.

109 ACA, Canc., Reg. 1537, f. 156v [1], véase f. 166r. 
remuneración de 100 y 200 sueldos anuales (presbíteros y confesores) ${ }^{110}$. Leonor de Sicilia obligó a los beneficiarios la obediencia de la abadesa siguiendo el modelo de las clarisas de Barcelona y haciendo referencia con esta expresión probablemente a Santa Maria de Pedralbes ${ }^{111}$. Este modelo de la cura de almas es notable, ya que en Teruel existía un convento de franciscanos que, al parecer, o no estaba involucrado en la administración de Santa Clara o lo estaba muy poco. No se conocen fuentes en las que conste la relación entre los monasterios de la primera y la segunda orden. Tampoco se documentan pruebas sobre la ejecución del mencionado permiso del 8 de marzo de 1351 por parte del ministro general de los franciscanos a la reina, es decir, el permiso por el cual Leonor de Sicilia habría ejercido el derecho de nombrar frailes para la administración de los sacramentos y la instrucción de las hermanas ${ }^{112}$. En los asuntos jurídicos que no se referían a los derechos de la orden clarisa, Santa Clara estaba sometida directamente al representante del arzobispo de Zaragoza que residía en Teruel ${ }^{113}$. Tanto los residentes del monasterio como aquellas personas estrechamente vinculadas a él se pueden reconstruir fragmentariamente. Complementando la información sobre la dotación económica con los pocos datos sobre la estructura social y las relaciones sociales, Santa Clara de Teruel se presenta como un convento pequeño y bien dotado que disponía, al menos en teoría, de una buena cura de almas.

Las obligaciones del convento de rezar por sus benefactores que tenían que cumplir las monjas como compensación por la dotación se detallaban minuciosamente en el acta fundacional. Aunque no se conserva ninguna copia del acta, las obligaciones se copiaron en las donaciones del censo de 1368 y 1372 y además en el codicilo de Leonor de Sicilia ${ }^{114}$. Se distinguió entre el tiempo de vida de Pedro IV y Leonor de Sicilia y aquel después de su óbito. Las oraciones durante la primera fase estaban dedicadas a los padres de Leonor de Sicilia, los reyes Pedro II de Sicilia (1337-1342) y su esposa Isabel de

110 A. Castellano, Pedralbes, pp. 54-55; J. Webster, Franciscans, p. 309.

111 ACA, Canc., Reg. 1537, f. 156v [1], v. f. 166v: "Et ipsi presbiteri et scolares sint sub obedientia dicte abbatisse, in hiis que celebrationem officiorum divinalium in dicta ecclesia et monasterio concernant, et sibi pareant et obediant in aliis mandatis suis licitis et honestis, prout faciunt ceteri presbiteri ecclesiastica beneficia obtinentes in ecclesia sororum minorum Barchinone".

112 Véase nota 28.

113 ACA, Canc., Reg. 1537, f. 156v [1], v. f. 167r-167v: "Et ad hoc eam teneri volumus et compelli posse iubemus per officialem archiepiscopi Cesarauguste residentem in dicta civitate Turoli, iuris remediis quibus decet, salvo dicto monasterio et abbatisse ac sororibus eiusdem in omnibus aliis privilegiis exemptionis dicti ordinis, per quod fratres et sorores eiusdem ordinis a subjectione et iurisdictione ordinariorum sunt exempti".

114 La lista es en todos los documentos idéntica. Como base de las citas se usa la primera donación del censo, es decir ACA, Canc., Reg. 1577, f. 106v [1], Barcelona, 1368 diciembre 10. 
Carintia (que murió después de 1352), y además a la salvación de las almas de todos los difuntos. Las almas de Pedro IV y Leonor de Sicilia se debieron incluir después de su muerte en las oraciones. Según la regla de la orden, las clarisas tenían que rezar una serie determinada de oraciones al final de las Horas, es decir ciertos versos, responsorios y antífonas ${ }^{115}$. Cabe destacar que, aparte de rezar por la familia real, mencionan varias veces a santa Catalina, lo cual pone de relieve la veneración que se le tenía en estas oraciones. Las hermanas legas tenían que rezar mientras tanto cinco padrenuestros, también por veneración de la santa Catalina, y siete avemarías por la Virgen María ${ }^{116}$. Al final de la misa mayor tenían que rezar los siete salmos penitenciales con toda la letanía $a^{117}$. Además, el cura que llevaba a cabo la misa tenía que celebrar dos oraciones finales por la prosperidad de la casa de los reyes de Aragón y la salvación de las almas de la familia donadora ${ }^{118}$. Todos los lunes tenían que decirse dos misas memoriales por las almas de los progenitores de Leonor de Sicilia, Pedro II de Sicilia (1337-1342) e Isabel de Carintia ${ }^{119}$. Los salmos cantados debían terminarse con una pequeña doxología y cada hermana tenía que leer en un plazo de dos semanas un salterio completo por el bienestar de la casa real ${ }^{120}$. Las hermanas legas y las monjas que no sabían leer tenían que

115 Ibidem, "viventibus serenissimo domino Rege, viro et domino nostro carissimo, et nobis et altero nostrum in fine orarum cuiuslibet dierum, quas ex provisione vestre regule tenemini dicere, versum «Ora pro nobis sancta Dei genetrix» cum responso «Ut digni efficiamur promissionibus Christi», Oremus: «gratiam tuam quesumus, Domine, mentibus nostris infunde etc. », etiam antiphonam beate Katerine «Veni sponsa Christi etc. », versum «Ora pro nobis beata Katerina», responsum «Ut digni etc.», versum «Domine, salvum fac Regem nostrum cum Regina et liberis suis», responsum et «Exaudi etc.», versum «Mitte eis, Domine, auxilium de sancto», responsum «De Sion etc.» Oremus: «Deus, qui dedisti legem Moysi etc.»."

116 Ibidem: "Item sorores layce, ignorantes litteris tenentur dicere quelibet in fine dictarum orarum quinquies Pater noster in reverentiam beate Katerine et septies Ave Maria in reverentiam beate Marie".

117 Ibidem: "Etiam in fine misse maioris quam celebrabitis quacumque die tenemini dicere septem psalmos penitentiales cum tota letania".

118 Ibidem: "Item qualibet die tenemini dicere et celebrari facere in ecclesia maiori dicti monasterii duas missas celebratas alta voce. Et in prima faciatis et fieri faciatis per sacerdotem celebrantem dictam primam missam commemorationem in secreto altaris de domo Aragonum pro conservatione et prosperitate sua et pro vita dicti domini Regis et nostra, dicto domino Rege et nobis viventibus. Secunda et ultima vero missa cuiuslibet diei celebretur pro defunctis videlicet de requiem alta voce pro animabus dictorum parentum nostrorum, nobis viventibus, et post obitum dicti domini Regis et nostrum pro animabus sua et nostra et alterius nostrum defuncti etiam vivente altero".

119 Ibidem: "Item, viventibus dicto domino Rege et nobis, qualibet die lune cuiuslibet septimane tenemini facere unum solenne anniversarium pro anima domini Petri et domine Elisabet, bone memorie Regis et Regine Sicilie, patris et matris nostrorum".

${ }^{120}$ Ibidem: "Item quelibet soror dicti monasterii de hiis, que sunt et erunt in dicto monasterio sciens litteras, viventibus dicto domino Rege et nobis, de duabus in duabus septimanis continue tenentur legere et dicere unum psalterium integrum cum «Gloria Patri etc.» in fine cuiuslibet psalmi, ita quod quelibet earundem sororum infra spatium duarum septimanarum tenetur dice- 
cumplir con obligaciones ligeramente diferentes. En vez de leer el salterio debían rezar trescientos padrenuestros ${ }^{121}$. Dichas obligaciones nos informan de una manera muy detallada de las formas y ritos de la memoria y de la praxis litúrgica en un monasterio femenino bajomedieval. La fundadora ejercía a través de estas disposiciones una fuerte influencia en la organización de estos aspectos. La práxis de la memoria en Santa Clara de Teruel recuerda a aquella de Santa Maria de Pedralbes, donde se determinaron por parte de la fundadora Elisenda de Montcada normas precisas muy parecidas ${ }^{122}$. En cambio, en Santa Clara de Teruel las condiciones parecen más estrictas que en Pedralbes.

Sobre la decoración de la iglesia conventual y la asignación de obras artísticas se pueden dibujar algunos trazos de forma incompleta ${ }^{123}$. Aparte de la dotación económica en el momento de la fundación, Santa Clara también recibió algunos objetos de arte, entre ellos, un retablo con la imagen de la santa Catalina y un relicario. Ambos fueron diseñados por el pintor Lorenzo de Zaragoza ${ }^{124}$. Tal vez los restos del retablo sean las tablas con las imágenes de la santa Catalina y de san Miguel en el Museo diocesano en Teruel ${ }^{125}$. Además, Santa Clara de Teruel disponía de una colección de libros que se puede reconstruir de forma muy fragmentaria. Así se pueden identificar unos encargos por parte de Leonor de Sicilia de libros destinados a su fundación, por ejemplo, dos misales, que se compraron y encuadernaron respectivamente en agosto de 1367 y enero de 1368 en Barcelona y Zaragoza ${ }^{126}$, y una colección hagiográfica (flos sanctorum) ${ }^{127}$. Un breviario encuadernado en cuero rojo, que hizo comprar Leonor de Sicilia el 11 de diciembre de 1374 en Barcelona, se entregó en febrero de 1375 por orden suya al monasterio ${ }^{128}$. Aparte de estas

re unum psalterium et aliarum duarum septimanarum aliud et sic continue pro conservatione et prosperitate ac vita domini Regis et nostra et domus Aragonum”. Sobre doxología véase H. Meyer, Art, Doxologie, col. 1337.

${ }^{121}$ ACA, Canc., Reg. 1577, f. 106v [1]: "Cetere vero sorores layce et ignorantes litteras dicti monasterii tenentur loco psalterii dicere trecentesies orationem dominicam scilicet Pater Noster pro animabus predictis".

122 A. Castellano, Pedralbes, pp. 199-202.

${ }^{123}$ Sobre el mecenazgo de Leonor de Sicilia para Santa Clara de Teruel véase O. Taravilla, Perfiles, pp. 34-42.

${ }_{124}$ A. Rubió, Documents, vol. 1, nº. 218, pp. 213-214: "in altero reetabulo est depicta istoria sancte Katerine"; así como ibidem, vol. 2, no. 153, p. 154. El retablo probablemente se envió en abril de 1367 a Zaragoza. En este momento se pagaron 81 sueldos jaqueses y 4 dineros para el transporte de un retablo y dos cajas con ropa de Tortosa a Zaragoza, que se enviaron desde allá a Teruel, véase M. Anglada, Els quatre llibres, p. 185.

125 S. Sebastián, A. Solaz, Teruel, p. 208.

126 A. Rubió, Documents, vol. 2, n $\mathrm{n}^{\circ} 157$, pp. 156-157 (enero de 1368) e ibidem, nota 1 para el segundo misal (agosto de 1367, edición incompleta).

${ }^{127}$ Ibidem, Documents, vol. 2, $\mathrm{n}^{\circ} 165$, p. 161.

${ }^{128}$ M. Anglada, Els quatre llibres, p. 87. 
noticias escasas, es difícil estimar el desarrollo posterior y el volumen de la colección de libros.

La reina donó también otros objetos preciosos a Santa Clara, de los cuales se atestiguan, por lo menos, un anillo de oro y un báculo que fueron robados en $1445^{129}$. Las monjas conservan todavía hoy en día un báculo del siglo XIV que bajo el nombre de "Báculo de la reina" se atribuye a Leonor de Sicilia $^{130}$. Es muy posible que se trate del báculo donado por la reina, si bien esta cuestión requiere ser investigada con más profundidad. Igualmente faltan indicios de las reliquias que el monasterio sin duda tenía en su posesión. No está documentado ningún esfuerzo concreto por adquirir algunas reliquias por parte de Leonor de Sicilia durante su vida. Sin embargo, dejó en su testamento una gran parte de su colección al monasterio turolense. La reina dispuso que de aquellas reliquias que todavía no se habían engastado en oro o plata se entregase la parte más valiosa e importante a las clarisas, mientras que el resto tenía que repartirse entre los infantes Martín y Leonor ${ }^{131}$. Con estas pruebas se agotan los indicios de las donaciones por parte de la fundadora. Francesco Gonzaga proporciona algunos detalles sobre las reliquias guardadas en Santa Clara sin indicar el origen de ellas. Según él, el convento turolense poseía unas partes de la Vera Cruz y del fundador de la orden, San Francisco ${ }^{132}$. Con certeza, se conocen datos de nuevas donaciones posteriores solamente después de un vacío en el tiempo, ya en el siglo XVI. Juan Gaspar Sánchez Muñoz donó, según su propia narración, en 1512 una reliquia de san Honorato junto con un reliquiario de plata ${ }^{133}$. Tres años después hizo erigir una capilla con un retablo y una ornamentación adecuada para guardarlos en la iglesia del monasterio ${ }^{134}$. Aunque Juan Gaspar Sánchez Muñoz debió haber tenido cierta preferencia por Santa Clara de Teruel a causa de sus relaciones familiares, no desatendió las demás instituciones religiosas de la ciudad. Sin embargo, pese a los pocos datos presentados, estos indican que se trataba de un convento que estaba dotado de forma opulenta.

129 Véase notas 93 y 94.

${ }^{130}$ Véase fig. 2.

131 M. García, El entorno, p. 349; U. Deibel, La reyna Elionor, p. 391; ACA, Canc., Reg. 1537, f. 139r [1], Barcelona, 1374 junio 12, cita f. 151r: "Volumus insuper et ordinamus quod reliquie sanctorum in posse nostro existentes, que tamen non sunt encastate seu munite in auro vel argento, diuidantur iuxta arbitrium dictorum quatuor ultimorum manumissorum nostrorum. Et detur monasterio minorissarum Turolii maior et pulcrior pars ex eis. Et cetere reliquie dividantur inter dictos infantem Martinum et infantissam Alienoram equibus partibus arbitrio dictorum quatuor manumissorum".

${ }^{132}$ F. Gonzaga, Origine, p. 710: "Habentur \& in eiusdem sacrario Dominicae crucis particula, \& cordae, qua seraphicus pater noster Franciscus pręcingi assueuerat, bona pars".

133 G. Sánchez, Diario, pp. 14-15; el hijo primogénito de Juan Gaspar Sánchez Muñoz llevaba el mismo nombre, véase G. Navarro, Muñoces, p. 742.

${ }^{134}$ G. Sánchez, Diario, p. 23. 
Entre 1410 aproximadamente y 1600 las fuentes son más escasas. Principalmente se encuentran pagos por parte de ciudadanos o habitantes de la ciudad y de la comunidad de las aldeas de Teruel. Dos momentos claves se refieren a la pertenencia del monasterio y a su estructura. El fraile observante Alonso de Guadalajara reformó en 1496 Santa Clara de Teruel por orden real, tal y como atestigua la Crónica de los jueces de Teruel. Según ella, se expulsó a la abadesa y a otras tres monjas del monasterio y los frailes observantes se encargaron de la cura de almas de las hermanas. La crónica expone que la reforma se llevó a cabo de una forma similar en el resto de Castilla y Aragón ${ }^{135}$. La reforma fue llevada a cabo por los reyes Isabel de Castilla y Fernando II de Aragón por iniciativa del confesor de Isabel, Francisco Jiménez de Cisneros. El Diario turolense informa de que 15 años más tarde se revocó el cambio y se restituyeron los dos conventos franciscanos en Teruel, San Francisco y Santa Clara, a los conventuales ${ }^{136}$. Según Lucas Wadding, el cambio definitivo de los conventuales a los observantes tuvo lugar en $1567^{137}$. En el marco de la reforma de la orden por el rey Felipe II, Gregorio XIII donó el 15 de junio de 1578 los bienes de los franciscanos de Teruel a las clarisas ${ }^{138}$. Esta transferencia tuvo lugar poco después de la institución de un obispado, exactamente en 1577, y coincidió, por tanto, con un tiempo turbulento en la ciudad. En todo caso, para esta fase posterior es necesario buscar más fuentes que permitan documentar mejor la historia del monasterio.

\section{CONCLUSIONES: LEONOR DE SICILIA Y EL POTENCIAL DE SU PROMOCIÓN ESPIRITUAL}

Estos comentarios solamente ofrecen un esbozo sobre la fundación y el desarrollo de Santa Clara de Teruel en los primeros años y décadas de su existencia. Sin embargo, gracias a las fuentes que conocemos, se puede reconstruir de una manera muy detallada esta fase en la historia de un monasterio casi por completo desconocido hasta el día de hoy. Sobre todo, de su

135 J. Caruana, Una relación, p. 275; F. López, Crónicas, pp. 310-311. La datación del año 1496 debería ser correcta, ya que se menciona la boda de Juana I con Felipe I de Habsburgo. Sin embargo, esta indicación no está de acuerdo con la orden de la reforma en el año 1493. Sobre la reforma véase J. García, Conventualismo, pp. 282-284. Las fuentes indicadas por J. García (Ibidem, p. 282, n. 54 con referencia a ACA, Canc., Reg. 3611) no mencionan Teruel, así que parece plausible una reforma posterior de Santa Clara.

136 G. Sánchez, Diario, p. 10. Los conventuales no se mencionan en el texto y curiosamente se dejó un espacio en el párrafo en cuestión pero otro sentido no debería entrar en consideración.

${ }^{137}$ L. Wadding, Annales, p. 220.

${ }^{138}$ ASV, Armadio XLII, 34, f. 431r-433r, Roma, 1578 junio 15. 
estudio cabe destacar que Santa Clara de Teruel fue un proyecto muy ambicioso de su fundadora, la reina Leonor de Sicilia. Probablemente en el convento se asentaron inicialmente monjas de Santa Catalina de Zaragoza, lo cual, sin embargo, no se puede comprobar con absoluta certeza. Se pretendió crear un convento pequeño, pero muy bien dotado y, para llevar a cabo esta idea, se le dedicó sobre todo entre la mitad de los años sesenta y setenta del siglo XIV gran atención por parte de ambos reyes Pedro IV y Leonor de Sicilia. En todo caso, queda claro que la reina -a pesar de la participación de su esposo- fue el personaje decisivo en la institución del convento. La reina mostró durante toda la realización de esta tarea una gran perseverancia y consideración y cumplió con el deber principal como fundadora ${ }^{139}$. La suposición de que Santa Clara de Teruel era su proyecto más importante, queda atestiguada por las fuentes de una forma muy evidente. A iniciativa de Leonor de Sicilia, el monasterio obtuvo una dotación riquísima en privilegios e ingresos, tanto por parte de Pedro IV como por parte de la Curia Romana. La reina, por su parte, ejerció una fuerte influencia en la vida religiosa de las monjas y las obligó a cuidar intensamente la memoria dinástica. Aparentemente, poco después de la muerte de Leonor de Sicilia, se truncaron las relaciones entre la casa real y el monasterio. Ciertamente, los soberanos continuaron ejerciendo su influencia en asuntos importantes concernientes a Santa Clara, pero se interrumpió la generosa donación de bienes y limosnas. El enorme monto de la dotación de Leonor de Sicilia al monasterio de Teruel, comparado con las de otros monasterios, y la nueva orientación del patronazgo religioso dirigido por Martín I y su esposa María de Luna contribuyeron tal vez al declive del interés por parte de la monarquía. Sin embargo, el papel más importante en este sentido muy probablemente lo desempeñó el cambio dinástico y el inicio del reinado de los Trastámara. Es probable que Santa Clara de Teruel pasara a ser, a partir del siglo XV, más importante para la nobleza local y regional que para la monarquía, si bien no se puede aportar al respecto información más detallada a partir de las fuentes usadas en el presente estudio. Sobre todo, quedan por aclarar la interacción entre la ciudad y su único convento femenino, así como su estatus y la función social que tuvo en el marco local. Estos aspectos serían muy interesantes en el caso de Santa Clara de Teruel, ya que se trata de un monasterio que cambia su esfera de influencia: de la real a la municipal ${ }^{140}$.

Finalmente, parece claro que los acicates para instituir el convento de clarisas de Teruel fueron, sobre todo, la cura de la memoria dinástica y la implementación de la presencia real en el Aragón meridional. Con la elección

139 M del M. Graña, Reinas, p. 25.

${ }^{140}$ Sobre la distinción entre diferentes esferas de poder véase $\mathrm{M}^{\mathrm{a}}$ del M. Graña, Religiosas, p. 378 .

ANUARIO De Estudios Medievales, 44/1, enero-junio 2014, pp. 141-178 ISSN 0066-5061, doi:10.3989/aem.2014.44.1.05 
de un lugar de gran valor simbólico en la ciudad, es decir, el palacio real, Leonor de Sicilia consiguió destacar particularmente su presencia. Aparte de esto, las fuentes conocidas no dejan entrever otros motivos para su fundación ${ }^{141}$. Así, la fundación del convento, debe ubicarse probablemente en el contexto de la promoción general de Teruel por parte de Pedro IV, complementada por Leonor de Sicilia con la creación de un convento claramente real. En todo caso, las fuentes indican una fuerte motivación política por parte de la reina para su establecimiento. Además, Santa Clara se presenta como el convento que contó con el mayor apoyo de su parte, lo que nos obliga a asumir también una motivación religiosa importante. Dado el gran interés de Leonor de Sicilia por las reliquias resulta sorprendente que no se documente ningún esfuerzo explícito por conseguir alguna de estas reliquias para las clarisas aparte del legado testamentario. Faltarían con todo dos componentes más para establecer una conexión estrecha y clara entre la reina y Santa Clara de Teruel: en primer lugar, Leonor de Sicilia nunca previó recibir sepultura en el convento turolense, sino que por el contrario prefirió ser enterrada junto a su esposo en Poblet o en cualquier lugar que escogiera Pedro IV, según consta en su codicilo. Este hecho es notable porque en la Corona de Aragón las reinas no solían enterrarse junto a sus esposos ${ }^{142}$. Además, generalmente las fundaciones servían a las fundadoras como lugar de sepultura ${ }^{143}$. Por la preferencia del panteón real, Leonor destacó su pertenencia a la dinastía más bien que individualizarse mediante un enterramiento individual. Sin embargo, no hay que sobrevalorar estos hechos, ya que es normal que la sepultura en panteón real se considerase más prestigiosa que el entierro en un convento particular. En cambio, por la ausencia de una tumba real, a Santa Clara le falta un lugar emblemático que resalte su status como en Pedralbes. En segundo lugar, Leonor de Sicilia no visitó nunca personalmente el monasterio, lo que pudo deberse a los tiempos difíciles y turbulentos que sobrevinieron al final de la guerra contra Castilla y por los problemas de salud de la propia soberana. Pero esto nos impide concluir la existencia probada de un contacto directo o estrecho entre la fundadora y el convento a pesar de que sin ninguna duda la dotación de Santa Clara de Teruel sitúa al convento como la institución religiosa que, entre todos los otros conventos promocionados por ella, es decir, Santa María

${ }^{141}$ Posiblemente la enfermedad de Leonor de Sicilia en el verano tardío de 1367 contribuyó a la dotación de Santa Clara pero no se encuentran testimonios directos en las fuentes. Pedro IV se mostró en septiembre de 1367 varias veces muy preocupado sobre el estado de salud de su esposo. En el caso de una enfermedad más larga, una conexión entre su salud y la dotación de Santa Clara podría ser posible. Véase ACA, Canc., Reg. 1218, f. 2r [1], Zaragoza, 1367 septiembre 5, e Ibidem, 15r [1], Zaragoza, 1367 septiembre 22.

${ }^{142}$ E. McKiernan, Reception, pp. 342-343.

${ }^{143} \mathrm{M}^{\mathrm{a}}$ del M. Graña, Reinas, p. 24. 
de Sigena, Santa Agnés de Calatayud y Sant Antoni de Barcelona, gozó de mayores privilegios por parte de Leonor de Sicilia ${ }^{144}$. Probablemente, el patronazgo religioso hacia Santa Clara de Teruel sirvió como modelo para María de Luna que se educó en la corte de Leonor de Sicilia. María de Luna también dotó el convento franciscano de Sancti Spiritus, destinado a la reforma de la orden franciscana, en València con ingresos de 5.000 sueldos $^{145}$. Pero para poder fundamentar esta suposición hacen falta todavía estudios sobre otros conventos y su dotación por parte de las reinas. Sin embargo, la dotación de Santa Clara es un indicador de su status en el sentido expresado por Gregorio IX: Un sustento suficiente para garantizar la clausura estricta y el desempeño de los deberes espirituales ${ }^{146}$.

El patronazgo de Santa Clara de Teruel por parte de Leonor de Sicilia cumplía con todos los requisitos necesarios para la fundación de un monasterio, tal como que se ha esbozado al inicio de este estudio. La larga duración, casi 20 años, desde que se trazan los planes iniciales hasta la realización misma del proyecto, es una prueba de la férrea voluntad de la fundadora de ejecutarlo. El sustento del convento se realizó a través de donaciones generosas que sobrepasan a otras de su tiempo. Leonor de Sicilia aprovechó su influencia como reina no solo en Teruel sino también con su esposo, con las autoridades eclesiásticas regionales y con la Curia Romana. Sin embargo, sus esfuerzos no duraron más allá de su muerte. El interés de la casa real por Santa Clara de Teruel disminuyó a partir del siglo XV y en su lugar diversas estirpes regionales y locales comenzaron a promocionar el convento, que seguía manteniendo el epíteto de "convento real". Por ello, tan solo podemos considerar Santa Clara de Teruel como convento real hasta cierto punto, por mucho que las intenciones de la fundadora aspiraran a gozar de este estatus. Lo más probable es que Leonor de Sicilia tomara como modelo a Santa Maria de Pedralbes para el monasterio turolense. Sin embargo, no parece muy verosímil que este pueda haber sido la única influencia. Todo apunta a que Leonor como infanta se educó en el convento de las clarisas en Messina ${ }^{147}$. Por lo tanto, es aquí donde se deberían buscar posibles modelos para la dotación y la configuración de Santa Clara de Teruel. También es necesario seguir investigando más fuentes en lo que respecta a la historia posterior del convento. A esto se suma la carencia de una historia de la ciudad de Teruel que ponga de relieve los cambios en la

${ }^{144}$ U. Deibel, Elionor, p. 424.

145 V.N. Silleras-Fernández, Power, pp. 116-117, p. 123, nota 62 sobre el legado extraordinario de María de Luna para las clarisas de Montblanc, e ibidem, p. 124, nota 74 sobre la dotación de Sancti Spiritus en Gilet con ingresos procedentes de censos.

${ }_{146}$ N. Jornet, Monestir, p. 96.

${ }^{147}$ U. Deibel, Elionor, p. 356. 
pertenencia a la Corona y a la cámara de la reina. Pedro IV donó la ciudad a su esposa Leonor de Sicilia y, por tanto, también el poder sobre la ciudad. Un análisis más pormenorizado y extensivo en el tiempo de Teruel podría contribuir a proporcionar un conocimiento más detallado de la política monárquica hacia la ciudad y de las relaciones entre esta y el convento y, por consiguiente, del status de Santa Clara de Teruel.

\section{BIBLIOGRAFÍA CITADA}

Anglada Cantarell, Margarida; Fernández Tortadés, Mª Àngels; Petit Cibiriain, Concepció (eds.), Els quatre llibres de la reina Elionor de Sicília a l'Arxiu de la Catedral de Barcelona, Barcelona, Fundació Noguera, 1992.

Bianchini, Janna, The Queen's Hand. Power and Authority in the Reign of Berenguela of Castile, Philadelphia, University of Pennsylvania Press, 2012.

Caruana Gómez de Barreda, Jaime, Una relación inédita de Jueces de Teruel, "Cuadernos de Historia de Jerónimo Zurita" 14-15 (1963), pp. 227280.

Castellano i Tresserra, Anna, Pedralbes a l'Edat Mitjana. Història d'un monestir femení, Barcelona, Publicacions de l'Abadia de Montserrat, 1998.

Deibel, Ulla, La reyna Elionor de Sicilia, "Memorias de la Real Academia de Buenas Letras de Barcelona" 10 (1928), pp. 349-453.

Dendorfer, Jürgen; Lützelschwab, Ralf (eds.), Geschichte des Kardinalats im Mittelalter, Stuttgart, Hiersemann, 2011.

Eubel, Konrad (ed.), Bullarium Franciscanum Romanorum Pontificum, constitutiones, epistolas ac diplomata continens tribus ordinibvs minorum, clarissarum et poenitentium a seraphico patriarcha Sancto Francisco institutis concessa, vol. VI, Roma, Typis Sacræ Congregationis De Propaganda Fide, 1902.

García Herrero, María del Carmen, El entorno femenino de los reyes de Aragón, en Sesma Muñoz, Ángel (ed.), La Corona de Aragón en el centro de su historia (1208-1458). La monarquía aragonesa y los reinos de la Corona, Zaragoza, Gobierno de Aragón. Departamento de Educación, Cultura y Deporte, 2010, pp. 327-350.

García Oro, José, Conventualismo y observancia. La reforma de las órdenes religiosas en los siglos XV y XVI, en González Novalín, José Luis (ed.), Historia de la Iglesia en España. III-1 ${ }^{\circ}$ : La Iglesia en la España de los siglos XV y XVI, Madrid, Ed. Católica, 1980, pp. 211-349. 
Garí, Blanca (ed.), Redes femeninas de promoción espiritual en los Reinos Peninsulares (s. XIII-XVI), Roma, Viella, 2013.

Gonzaga, Franciscus, De origine Seraphicae religionis Franciscanae eiusque progressibus, de regularis observanciae institutione, forma administrationis ac legibus, admirabilique eius propagatione, Roma, 1587.

Graña Cid, María del Mar, Religiosas y ciudades. La espiritualidad femenina en la construcción sociopolítica urbana bajomedieval (Córdoba, siglos XIII-XVI), Córdoba, Asociación Hispánica de Estudios Franciscanos, 2010.

Graña Cid, María del Mar, Reinas, infantas y damas de corte en el origen de las monjas mendicantes castellanas (c. 1222-1316). Matronazgo espiritual y movimiento religioso femenino, en Garí, Blanca (ed.), Redes femeninas de promoción espiritual en los Reinos Peninsulares (s. XIII-XVI), Roma, Viella, 2013, pp. 21-43.

Hebrera, José Antonio de, Chronica real serafica del reyno y santa provincia de Aragon de la regular observancia de nuestro Padre San Francisco, vol. II, Zaragoza, Diego de Larumbe, 1705.

Jornet i Benito, Núria, El monestir de Sant Antoni de Barcelona. L'origen $i$ l'assentament del primer monestir de clarisses a Catalunya, Barcelona, Publicacions de l'Abadia de Montserrat, 2007.

López, Atanasio, Documentos sobre el monasterio de Santa Catalina de Teruel, "Archivo Ibero-Americano" 4 (1915), pp. 429-431.

López, Atanasio, Convento de Santa Catalina de Teruel, "Archivo IberoAmericano" 7 (1917) pp. 442-446.

López Polo, Alberto, Catálogo del Archivo del Capítulo General Eclesiástico, Teruel, Instituto de Estudios Turolenses, 1965.

López Rajadel, Fernando (ed.), Crónicas de los jueces de Teruel (1176-1532), Teruel, Instituto de Estudios Turolenses, 1994.

López Rajadel, Fernando, Datación de la "Historia de los Amantes de Teruel". A través de los datos socioeconómicos del "papel escrito de letra antigua" copiado por Yagüe de Salas, Teruel, Fundación Amantes de Teruel, 2008.

McKiernan González, Eileen, Reception, Gender, and Memory: Elisenda de Montcada and her Dual-Effigy Tomb at Santa Maria de Pedralbes, en Martin, Therese (ed.), Reassessing the Roles of Women as Makers of Medieval Art and Architecture (Visualising the Middle Ages, 7), Leiden - Boston, Brill, 2012, vol. 1, pp. 309-352.

Meyer, Hans Bernhard, Art. Doxologie: III. Westkirche, 1.Liturgie, en Lexikon des Mittelalters, vol. III, Stuttgart, Metzler, 1986, col. 1337.

Moorman, John, A History of the Franciscan Order. From its Origins to the Year 1571, Oxford, Clarendon Press, 1968. 
Navarro Espinach, Germán, Muñoces, Marcillas y otras familias dominantes en la ciudad de Teruel (1435-1500), "Anuario de Estudios Medievales" 32 (2002), pp. 723-775.

Polo Rubio, Juan José, Eclesiásticos Turolenses del siglo XVI, "Hispania Sacra" 44 (1992), pp. 699-712.

Rodrigues, Ana Maria S.A., Espiritualidade e patrocínio religioso na Coroa Portuguesa no século XV: reis, rainhas e infantes, en Garí, Blanca (ed.), Redes femeninas de promoción espiritual en los Reinos Peninsulares (s. XIII-XVI), Roma, Viella, 2013, pp. 203-218.

Roussey, Marie Colette; Gounon, Marie Pascale, Nella tua tenda per sempre (sl 61,5). Storia delle Clarisse: Un'avventura di ottocento anni, Assisi, Ponziuncula, 2005.

Rubió i Lluch, Antoni, Documents per a la història de la cultura catalana medieval, 2 vols., Barcelona, Institut d'Estudis Catalans, 2000 (reimpresión facsímil de la edición Barcelona 1908-1921).

Sánchez Fuertes, Cayetano; Prada Camín, $\mathrm{M}^{\mathrm{a}}$ Fernanda, Reseña Histórica de los monasterios de Clarisas de España y Portugal, vol. I, Ávila, Hermanas Clarisas de España, 1996.

Sánchez Muñoz, Juan Gaspar, Diario turolense de la primera mitad del siglo XVI. Con introdución y notas por el Dr. D Gabriel Llabres y Quinta$n a, 2^{\mathrm{a}}$ ed., Madrid, Fortanet, 1902.

Sanz de Bremond y Mayans, Ana, Los documentos franciscanos de los conventos de la Corona de Aragón en el Archivo Histórico Nacional, "Archivo Ibero-Americano" 61 (2001), pp. 371-498.

Silleras-Fernández, Nuria, Power, Piety, and Patronage in Late Medieval Queenship: Maria de Luna, Nueva York, Palgrave Macmillan, 2008.

Sebastián, Santiago; Solaz, Ángel, Teruel monumental, Teruel, Instituto de Estudios Turolenses, 1969.

Taravilla Baquero, Olga, Perfiles de la promoción artística: la mujer bajomedieval en la Corona de Aragón, Màster en Iniciació a la Recerca en Humanitats, Girona 2008, URL: http://dugi-doc.udg.edu//handle/10256/1488 [consulta: 18/10/2013].

Trenchs, José; Aragó, Antonio Maria, Las cancillerías de la Corona de Aragón y Mallorca desde Jaime I a la muerte de Juan II, Zaragoza, Institución Fernando el Católico, 1982.

Ubieto Arteta, Agustín, Documentos para el estudio de la historia aragonesa de los siglos XIII y XIV: Monasterio de santa Clara, de Huesca, "Estudios de Edad Media en la Corona de Aragón" 8 (1967), pp. 547-701.

Ubieto Arteta, Antonio, Los monasterios medievales de Aragón: función histórica, Zaragoza, Caja de Ahorros de la Inmaculada de Aragón, 1999. 
Vincke, Johannes (ed.), Documenta selecta mutuas civitatis arago-cathalaunicae et ecclesiae relationes illustrantia, Barcelona, Biblioteca Balmes, 1936.

Wadding, Lucas, Annales minorum seu Trium Ordinum a S. Francisco institutorum, vol. VIII, Roma, Typis Rochi Bernabò, 1733.

Webster, Jill, Els franciscans catalans a l'edat mitjana. Els primers menorets $i$ menoretes a la Corona d'Aragó, Lérida, Pagès, 2000.

Webster, Jill, Deu documents sobre els problemes dels religiosos i dels eclesiàstics durant la lloctinença de la reina Maria de Castella, en Mutgé i Vives, Josefina; Salicrú i Lluch, Roser; Vela Aulesa, Carles (eds.), La Corona catalanoaragonesa, l'islam i el món mediterrani. Estudis d'història medieval en homenatge a la doctora Maria Teresa Ferrer i Mallol, Barcelona, CSIC, 2013, pp. 737-746. 


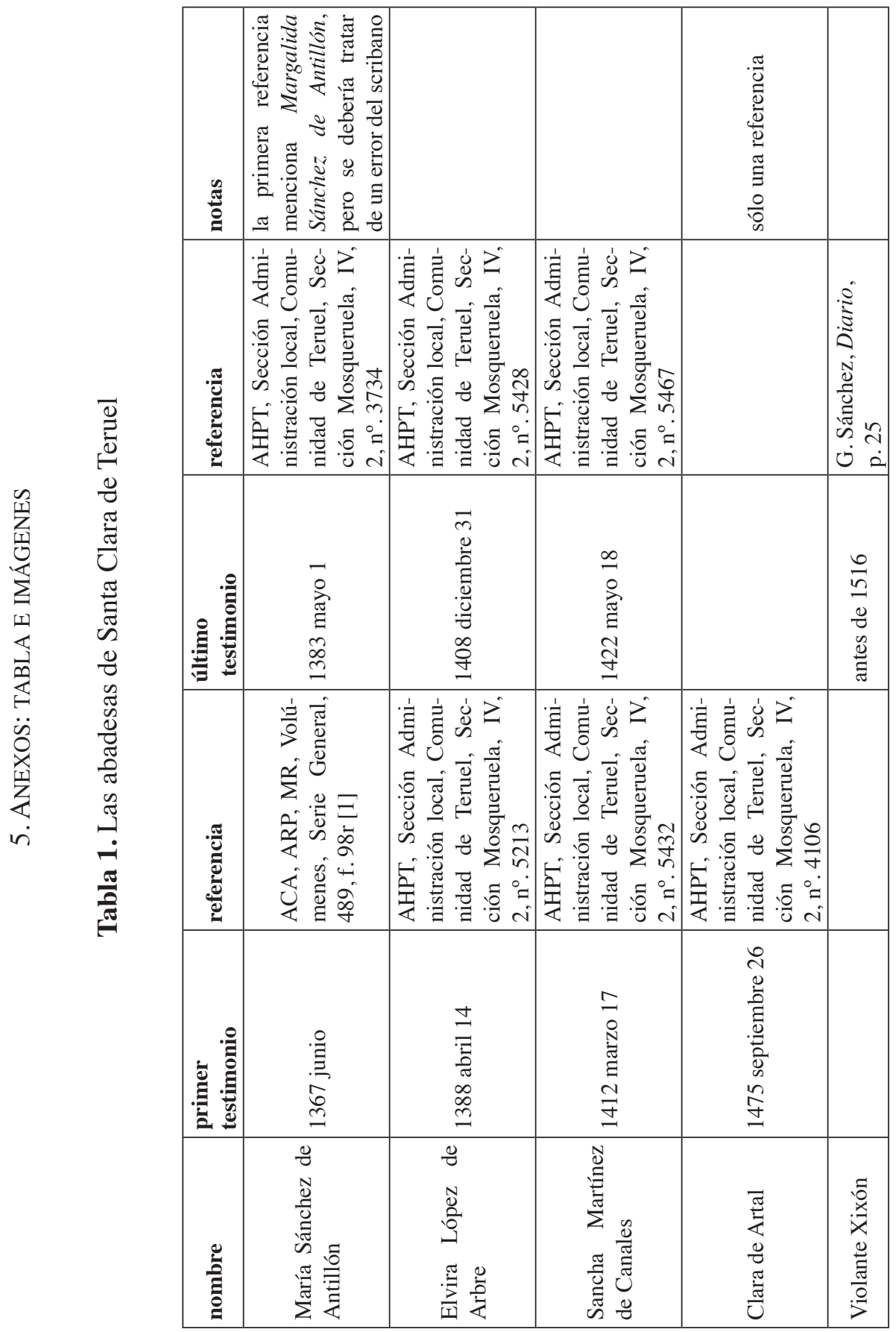

ANUARIO DE ESTUdios MedieVAles, 44/1, enero-junio 2014, pp. 141-178

ISSN 0066-5061, doi:10.3989/aem.2014.44.1.05 


\begin{tabular}{|c|c|c|c|}
\hline 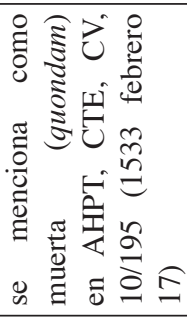 & & 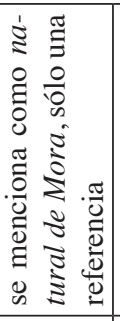 & \\
\hline 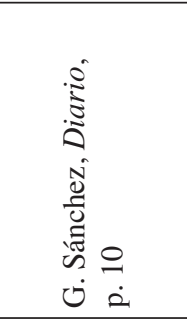 & 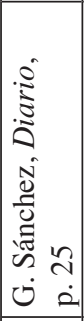 & & 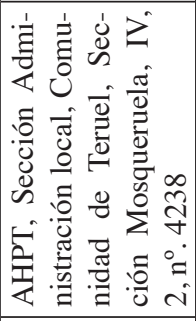 \\
\hline 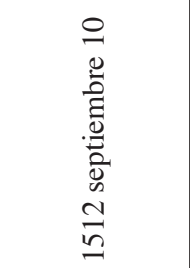 & 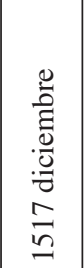 & & 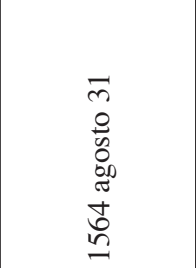 \\
\hline 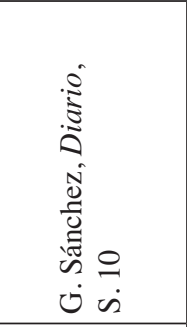 & 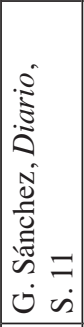 & 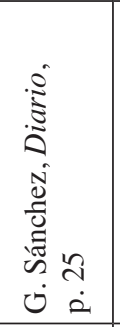 & 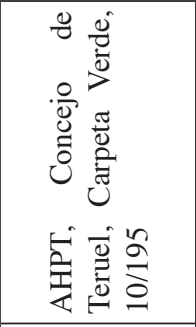 \\
\hline $\begin{array}{l}\stackrel{\circ}{\circ} \\
\stackrel{n}{2}\end{array}$ & 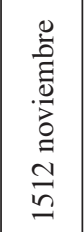 & 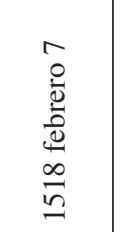 & 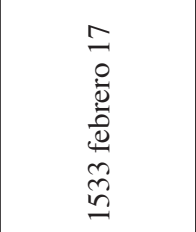 \\
\hline 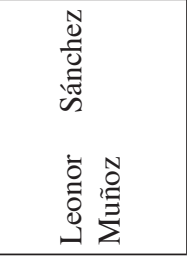 & 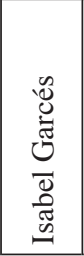 & 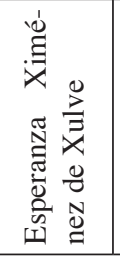 & 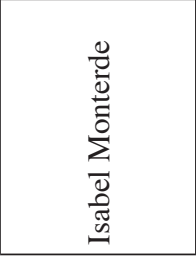 \\
\hline
\end{tabular}

ANUARIO De Estudios Medievales, 44/1, enero-junio 2014, pp. 141-178

ISSN 0066-5061, doi:10.3989/aem.2014.44.1.05 


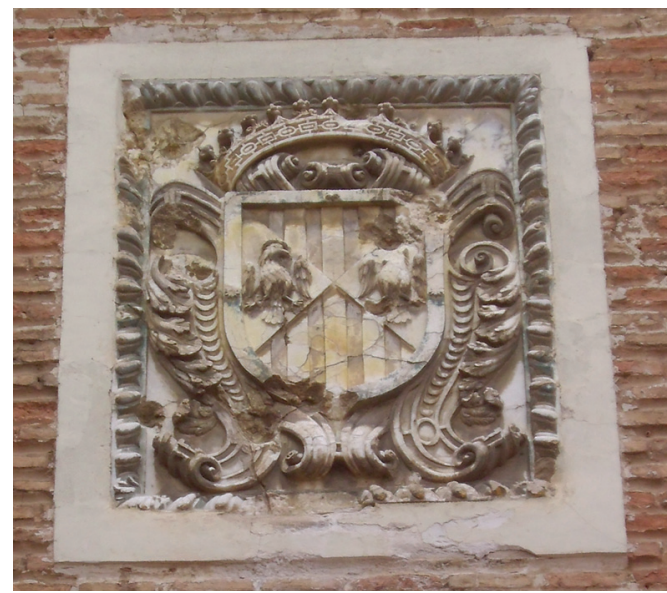

Fig. 1. Escudo de la dinastía siciliana, fachada de Santa Clara de Teruel.
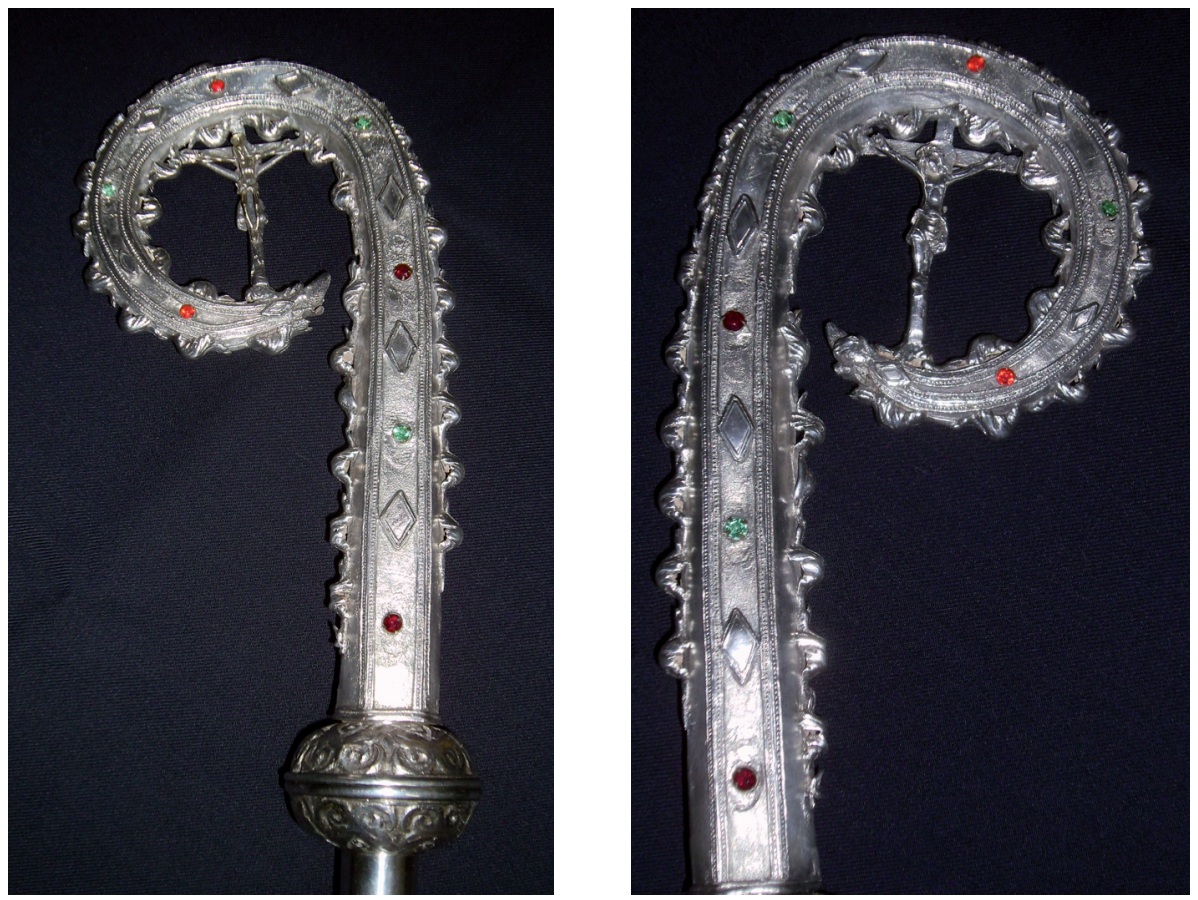

Fig. 2. Báculo de la reina.

Fecha de recepción del artículo: noviembre 2013

Fecha de aceptación y versión final: febrero 2014 